\title{
Requirement for DNA Ligase IV during Embryonic Neuronal Development
}

\author{
Susanne A. Gatz, ${ }^{1,2 \star}$ Limei Ju, ${ }^{2}$ Ralph Gruber, ${ }^{3}$ Eva Hoffmann, ${ }^{2}$ Antony M. Carr, ${ }^{2}$ Zhao-Qi Wang, ${ }^{3,4}$ Cong Liu, ${ }^{1,2 *}$ \\ and Penny A. Jeggo ${ }^{2}$ \\ ${ }^{1}$ Development and Stem Cell Institute, Key Laboratory of Ministry of Education, Department of Paediatrics, West China Second University Hospital, \\ Sichuan University, Chengdu, China 610041, ${ }^{2}$ Genome Damage and Stability Centre, University of Sussex, East Sussex, BN1 9RQ, United Kingdom, ${ }^{3}$ Leibniz \\ Institute for Age Research, Fritz Lipmann Institute, D-07745 Jena, Germany, and ${ }^{4}$ Faculty of Biology-Pharmacy, Friedrich Schiller University of Jena, \\ D-07745 Jena, Germany
}

The embryonic ventricular and subventricular zones (VZ/SVZ) contain the neuronal stem and progenitor cells and undergo rapid proliferation. The intermediate zone (IZ) contains nonreplicating, differentiated cells. The VZ/SVZ is hypersensitive to radiation-induced apoptosis. Ablation of DNA non-homologous end-joining (NHEJ) proteins, XRCC4 or DNA ligase IV (LigIV), confers ataxia telangiectasia mutated (ATM)-dependent apoptosis predominantly in the IZ. We examine the mechanistic basis underlying these distinct sensitivities using a viable LigIV ( ig $^{Y 288 C}$ ) mouse, which permits an examination of the DNA damage responses in the embryonic and adult brain. Via combined analysis of DNA breakage, apoptosis, and cell-cycle checkpoint control in tissues, we show that apoptosis in the VZ/SVZ and IZ is activated by low numbers of DNA double-strand breaks (DSBs). Unexpectedly, high sensitivity in the VZ/SVZ arises from sensitive activation of ATM-dependent apoptosis plus an ATM-independent process. In contrast, the IZ appears to be hypersensitive to persistent DSBs. NHEJ functions efficiently in both compartments. The VZ/SVZ and IZ regions incur high endogenous DNA breakage, which correlates with VZ proliferation. We demonstrate a functional $\mathrm{G}_{2} / \mathrm{M}$ checkpoint in VZ/SVZ cells and show that it is not activated by low numbers of DSBs, allowing damaged VZ/SVZ cells to transit into the IZ. We propose a novel model in which microcephaly in LIG4 syndrome arises from sensitive apoptotic induction from persisting DSBs in the IZ, which arise from high endogenous breakage in the VZ/SVZ and transit of damaged cells to the IZ. The VZ/SVZ, in contrast, is highly sensitive to acute radiation-induced DSB formation.

\section{Introduction}

DNA double-strand breaks (DSBs) arise from oxidative damage, replication, and exogenous sources, including ionizing radiation (IR). DSBs undergo repair and activate a signaling transduction process. The IR-induced damage responses relevant to this study are overviewed in Figure 1. Importantly, XRCC4 and DNA ligase IV (LigIV) are essential for DNA non-homologous end-joining (NHEJ), the major DSB repair mechanism, and their loss is embryonic lethal (Barnes et al., 1998; Frank et al., 1998; Gao et al., 1998).

LIG4 syndrome is a human disorder conferred by hypomorphic LigIV mutations (O'Driscoll et al., 2001). Patients show immunodeficiency, because NHEJ functions in $\mathrm{V}(\mathrm{D}) \mathrm{J}$ recombi-

\footnotetext{
Received March 15, 2011; revised May 9, 2011; accepted May 13, 2011.

Author contributions: S.A.G., C.L., and P.A.J. designed research; S.A.G., C.L., L.J., and R.G. performed research; S.A.G., C.L., E.H., A.M.C., Z.-Q.W., and P.A.J. analyzed data; S.A.G. and P.A.J. wrote the paper.

The Jeggo laboratory is funded by the Medical Research Council (United Kingdom), Association for International Cancer Research, the Wellcome Research Fund, the Department of Health (United Kingdom), and European Union Integrated Projects DNA-Repair Grant LSHG-CT-2005-512113 and Risc-Rad Grant FI6R-CT-2003-508842. C.L. was funded by the European Union Integrated Project DNA-Repair, and S.A.G. was funded by the Wellcome Research Fund. Z.-Q.W. and R.G. are funded by Deutsche Forschungsgesellschaft.

*S.A.G. and C.L. contributed equally to this work.

The authors declare no competing financial interests.

Correspondence should be addressed to P. A. Jeggo, Genome Damage and Stability Centre, University of Sussex,

Science Park Road, East Sussex, BN1 9RQ, UK. E-mail: p.a.jeggo@susssex.ac.uk.

DOI:10.1523/JNEUROSCI.1324-11.2011

Copyright $\odot 2011$ the authors $\quad 0270-6474 / 11 / 3110088-13 \$ 15.00 / 0$
}

nation, and microcephaly, which is observed at birth but is not progressive, suggesting a specific requirement for NHEJ during embryonic neuronal development.

Pioneering studies analyzing the neocortical ventricular/subventricular zones (VZ/SVZ) were made using the rat brain (Bayer et al., 1991). The VZ/SVZ, which lies adjacent to the ventricle, encompasses neuronal stem/progenitor cells. The murine VZ/ SVZ cells replicate rapidly between embryonic day 8 (E8) and E17 generating the intermediate zone (IZ), a predominantly nonreplicating, differentiated postmitotic layer (Pontious et al., 2008; Mitsuhashi and Takahashi, 2009). The IZ cells stain positively for Tuj1; the intermediate precursors of the SVZ, present predominantly at the basal layer of the VZ/SVZ close to the IZ, are Tbr2positive $\left(\mathrm{Tbr} 2^{+}\right.$) studies on $\operatorname{LigIV} V^{-1}$ mouse embryos that have shown high neuronal cell death from E11.5 to E14.5, declining at E16.5 (Barnes et al., 1998; Frank et al., 2000). Most apoptosis in LigIV $^{-1-}$ embryos occurs in IZ neurons (Gao et al., 1998; Orii et al., 2006; Shull et al., 2009). Collectively, studies with XRCC4/ LigIV null mice suggest that the IZ may suffer high DNA breakage. [Note that we use the recently accepted nomenclature for VZ/SVZ/IZ (Pontious et al., 2008)].

The embryonic brain is hyper-radiosensitive, with low doses (e.g., $0.125 \mathrm{~Gy}$ ) generating apoptosis in rodent embryos (Hoshino and Kameyama, 1988; Hoshino et al., 1991). IRinduced apoptosis in mouse embryonic brain occurs predominantly in the VZ/SVZ as early as $6 \mathrm{~h}$ after IR and is maximal when 


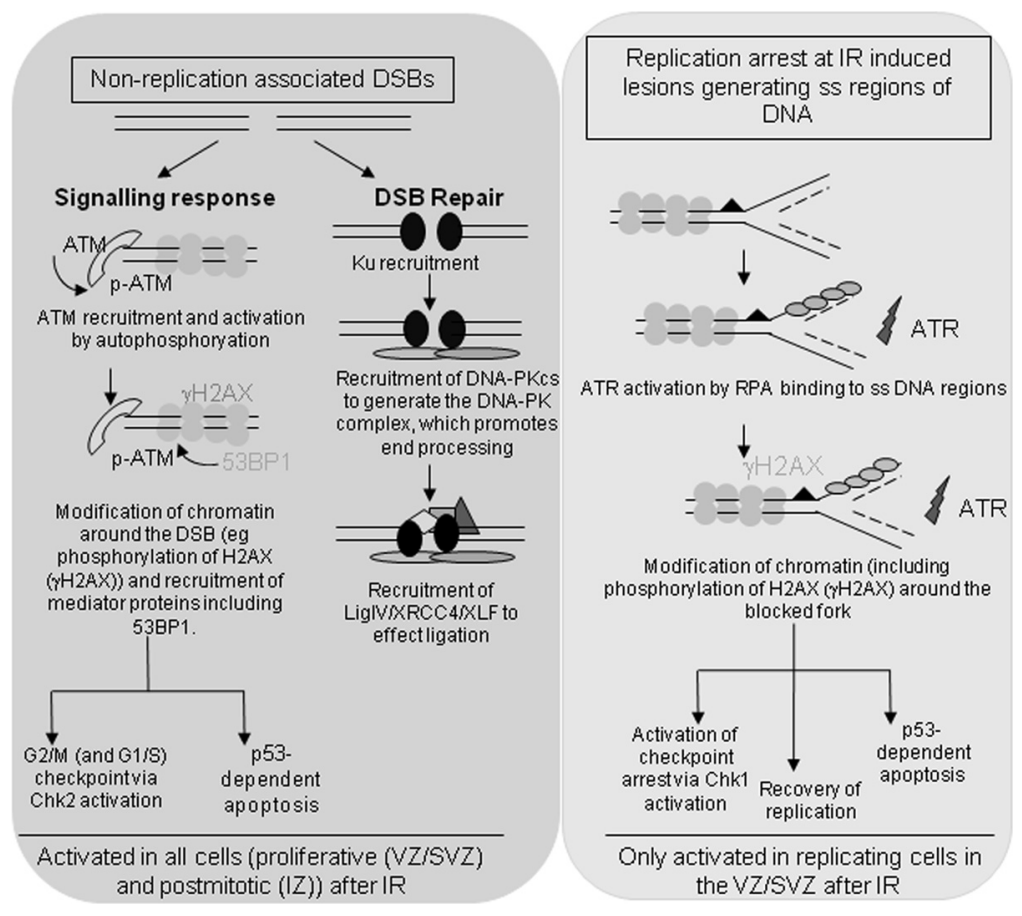

Figure 1. DNA damage responses of relevance to this study. IR exposure causes directly induced DSBs (left), base damage, and single-strand (ss) breaks (SSBs). Replication past any of these lesions can cause replication fork stalling/collapse and ss regions of DNA ( $>25$ nucleotides in length) (right). DSBs can also arise at collapsed forks. DSBs activate ATM signaling; ssDNA regions activate (ATM and ATR) signaling after its recruitment to replication protein A (RPA)-coated ssDNA regions of $>25$ nucleotides. SSBs of a few nucleotides do not activate ATM or ATR. ATM and ATR signaling can activate checkpoint arrest and p53-dependent apoptosis. DSBs are predominantly repaired by DNA NHEJ, which uses DNA ligase IV as the double-strand (ds) DNA ligase (HR can also function in late $S / G_{2}$ ). NHEJ involves binding of the Ku protein to dsDNA ends, recruitment of the catalytic subunit of the DNA-dependent protein kinase (DNA-PK), followed by end processing and recruitment of a ligation complex encompassing DNA ligase IV, XRCC4, and XLF. IR activates only ATM signaling in nonreplicating cells (e.g., IZ), but ATM and ATR can be activated in replicating cells attributable to the generation of ssDNA regions at stalled replication forks. 53BP1 does not play a major role in ATR signaling but amplifies ATM signaling by aiding the tethering of ATM at DSBs. 53BP1 is also required for the repair of $\sim 15 \%$ of DSBs (representing those that arise in heterochromatic DNA regions). $\gamma \mathrm{H} 2 \mathrm{AX}$ foci numbers closely respond to DSB formation in nonreplicating cells, cultured cell models; 53BP1 is recruited to all DSBs and the numbers of 53BP1 and $\gamma \mathrm{H} 2 \mathrm{AX}$ foci usually closely correlate in nonreplicating, cultured cells. The symbols are explained in the figure. Light circles on the DNA represent histones, and darker circles represent RPA bound to ss regions of DNA.

embryos are irradiated at approximately E13.5. IR-induced apoptosis in the IZ and endogenous apoptosis in $\mathrm{LigIV}^{-1-}$ embryos is ataxia telangiectasia mutated (ATM) dependent (Lee et al., 2001; Sekiguchi et al., 2001). However, in the VZ/SVZ after high doses $(>10 \mathrm{~Gy})$, apoptosis is ATM independent, raising the possibility that the VZ/SVZ does not sense DSBs (Lee et al., 2001; Abner and McKinnon, 2004). It has also been proposed that NHEJ does not function in the VZ/SVZ, which instead exploits homologous recombination (HR) for DSB rejoining (Orii et al., 2006). Furthermore, it has been suggested that stem cells do not repair DSBs but rather undergo apoptosis (Cairns, 2006). However, why the $\mathrm{VZ/SVZ} \mathrm{is} \mathrm{hypersensitive} \mathrm{to} \mathrm{IR-induced} \mathrm{apoptosis} \mathrm{whereas}$ LigIV-defective embryos succumb to apoptosis in the IZ is unknown.

The Lig4 ${ }^{\mathrm{Y} 288 \mathrm{C}}$ mouse carries a homozygous, hypomorphic mutation (Y288C) in LigIV (Nijnik et al., 2007). Like LIG4 patients, Lig ${ }^{\mathrm{Y} 288 \mathrm{C}}$ mice are small, immunodeficient, and, like $L i$ $g I V^{-1}$ mice, have enhanced apoptosis predominantly in the IZ. By examining DNA breakage, apoptosis, and cell-cycle checkpoint arrest in response to low IR doses, we provide mechanistic insight into the basis underlying the different apoptotic induction in control versus Lig4 ${ }^{\mathrm{Y} 288 \mathrm{C}}$ embryos.

\section{Materials and Methods}

Mice. Lig4 ${ }^{\text {Y288C }}(\mathrm{C} 57 \mathrm{BL} / 6)$ and $A T M^{-1-}$ (129/ $\mathrm{SV} \times \mathrm{C} 57 \mathrm{BL} / 6)$ mouse strains were generated as described previously (Barlow et al., 1996; Nijnik et al., 2007). Controls (designated ctrl) were either wild-type or Lig $4^{Y 288 C}$ heterozygous littermates of either sex. Analysis revealed no significant differences between them in the end points examined here. All animal experiments were performed in accordance with accepted standards of animal welfare and with approval by United Kingdom Home Office and permission of the responsible authorities of Thüringen/Germany. Animals were housed in a designated establishment for animal care and kept in a $12 \mathrm{~h}$ light/dark cycle. The day of the vaginal plaque was designated as E0.5 and the day of birth as postnatal day 0 (P0). Genotyping was performed from genomic DNA lysates isolated from the bodies (for E14.5/E17.5) or from tail tissue ( $\mathrm{P} 5$ and adult mice). PCR primers used to identify the wild-type and MUT LigIV alleles were as follows: forward, 5'-CTTAAAGCTTGGCATCAGTCAG-3'; and one of two sequence-specific reverse primers, reverse wild type, 5'-AACCGTTTCTGGAGAAGTACCGAT- $3^{\prime}$ or reverse mutant, $5^{\prime}$-AA CCGTTTCTGGAGAAGTACCGAC-3', respectively, generating a 310 bp PCR product. Genotyping for ATM was as described previously (Liao et al., 1999). For irradiation, we used a ${ }^{137} \mathrm{Cs} \gamma$-irradiation source (for doses $\geq 0.5$ Gy; Gammacell 40 or Gammacell 1000; Nordion) or an $\mathrm{x}$-ray machine (HS X-Ray System; A.G.O. Installation). For bromodeoxyuridine (BrdU) labeling, $50 \mathrm{mg} \mathrm{BrdU} / \mathrm{kg}$ body weight was delivered intraperitoneally to the pregnant mouse (E14.5). Analysis after exposure to $3 \mathrm{~Gy}$ was from a single embryo. All other analysis was from at least two embryos, and numbers of embryos used for quantifications are given in the figures.

Delineation of VZ/SVZ and IZ for quantification. At E14.5, the VZ/SVZ encompasses proliferating stem and progenitor cells. The IZ lies basal to the SVZ layer and consists of mostly differentiated postmitotic cells. BrdU pulse labeling shows an intense band of cells in the VZ/SVZ apical to the basal mitotic layer [identified by phospo-Histone $\mathrm{H} 3(\mathrm{pH} 3)$ staining] with very few replicating cells beyond this basal mitotic layer (Takahashi et al., 1995; Orii et al., 2006). We used pH3 staining to identify the basal mitotic layer and quantified p53-binding protein 1 (53BP1) foci formation or apoptosis either in the region from the ventricle up to and including the basal mitotic layer (VZ/SVZ) or within the differentiated IZ and cortical plate $(\mathrm{CP})$ layers. These zones were taken to represent regions that were engaged in replication (the VZ/SVZ) or predominantly nonreplicating (IZ/CP). The validity of this approach was verified by concomitant marker staining for Tbr2, a marker for intermediate SVZ progenitors, and Tuj1, a neuronal differentiation marker that stains the $\mathrm{IZ}$ and CP. The CP at E14.5 is small. It was included in the quantifications but is not labeled in the images.

Immunohistology. E14.5 embryo heads were snap frozen in liquidnitrogen-cooled isopentane after OCT embedment (LAMB/OCT; Thermo Fisher Scientific) or prefixed in 3\% paraformaldehyde (PFA)/ $2 \%$ sucrose/PBS, saturated with $30 \%$ sucrose/PBS and frozen after OCT embedment. For analysis of E17.5, P5, and adult mice, the brain was separated from the skull and snap frozen. Cryosections (sagittal, $7 \mu \mathrm{m}$ ) were performed on a Leica CM1900 cryostat. Before staining, snapfrozen samples were fixed in $3 \% \mathrm{PFA} / 2 \%$ sucrose/PBS for $10 \mathrm{~min}$ and 
lysed with $0.2 \%$ Triton X-100/PBS for $5 \mathrm{~min}$. Antigen retrieval (10 mM citrate buffer and $0.05 \%$ Tween $20, \mathrm{pH} 6.0$, for $40 \mathrm{~min}$ at $95^{\circ} \mathrm{C}$ ) was used for prefixed samples. All samples were blocked in $10 \%$ normal goat serum in PBS for $1-3 \mathrm{~h}$ (Sigma) (Santa Cruz Biotechnology for $\gamma \mathrm{H} 2 \mathrm{AX}$ staining in prefixed embryonic tissues). Immunofluorescence (IF) analysis of tissues was performed using the following primary antibodies: anti-53BP1 rabbit polyclonal (1:1000; A300-272A; Bethyl), antiphospho-S139 H2AX mouse monoclonal (1:1000; ab18311; Abcam), anti-BrdU rat monoclonal (1:150; ab6326; Abcam), anti-Tbr2 rabbit polyclonal (1:200-1:500; ab23345; Abcam), anti- $\beta$-Tubulin III rabbit (1:200; T2200; Sigma-Aldrich), anti-phospho-S10 Histone H3 mouse monoclonal (1:200; catalog \#9706S; Cell Signaling Technology), antiphospho-S10 Histone H3 rabbit polyclonal (1:200; 06-570; Millipore), and anti-Histone $\mathrm{H} 3$ (phospho-S10) mouse monoclonal (1:2000; ab14955; Abcam). Anti-pH3 antibody from Cell Signaling Technology only detects mitotic cells, whereas the anti-pH3 antibodies from Millipore and Abcam detect mitotic cells (bright pan-nuclear staining) and also $\mathrm{G}_{2}$-phase cells (speckled nuclear staining). Incubation of slides was done in a humidified chamber for $30 \mathrm{~min}$ at $37^{\circ} \mathrm{C}$ or $60 \mathrm{~min}$ at room temperature (RT). Secondary antibodies used were anti-rabbit Cy3 (1: 500) and anti-rat TRITC (1:150; both from Sigma), anti-mouse Alexa Fluor 488, anti-rabbit Alexa Fluor 488, and anti-mouse Alexa Fluor 555 (all 1:500; all from Invitrogen), and anti-rat TRITC and anti-rabbit Cy5 (1:200; Jackson ImmunoResearch). Sections were counterstained with 4',6-diamidino-2-phenylindole (DAPI) (0.05-0.1 $\mu \mathrm{g} / \mathrm{ml})$ and mounted with Vectashield (Vector Laboratories).

A Carl Zeiss Axioplan or Nikon eclipse microscope was used for image capturing (Simple PCI software). Quantifications were done by scrolling through the entire section depth at $100 \times$ magnification. Concomitant $\mathrm{pH} 3$ staining was used to define the basal mitotic layer between SVZ and IZ regions that coincides with the basal layer of Tbr2 ${ }^{+}$cells (see Fig. 2). For quantification of 53BP1 foci, snap-frozen or prefixed samples were used with comparable results. For all quantification (apoptosis, 53BP1 foci, mitotic index), the combined results for all sections derived from a single embryo were estimated, and the given results represent the mean and SD of the mean between embryos. $p$ values are estimated using the Student's unpaired $t$ test. DeltaVision Core and personalDV microscopes (Olympus) were used to visualize Cy5 staining and obtain images for Figure 7; imaging and deconvolution were performed with SoftWorx software (version 3.7.1), and images were further edited using Omero (version beta 4.1.1) and Photoshop (Adobe Systems).

TUNEL/neuronal marker/BrdU staining. Snap-frozen samples were used. TUNEL staining (In Situ Cell Death Detection kit, Fluorescein; Roche) was performed according to the instructions of the manufacturer. After fixation and permeabilization, the reaction mixture was added and samples were incubated for $1 \mathrm{~h}$ at $37^{\circ} \mathrm{C}$ in a darkened humidified chamber. TUNEL staining was performed after the IF staining ( $\mathrm{pH} 3$ or 53BP1 analysis) when performed in conjunction. For concomitant neuronal marker/TUNEL/BrdU staining, the neuronal marker staining was performed first as described above and then TUNEL staining was performed according to the instruction manual. After this, sections were refixed in 3\% PFA/2\% sucrose in PBS for $10 \mathrm{~min}$. After three washes, sections were denatured in $2.5 \mathrm{M} \mathrm{HCl}$ for $20 \mathrm{~min}$ at RT, washed for $10 \mathrm{~min}$ with PBS, and subjected to standard IF staining. For neuronal marker/ BrdU staining, after fixation and permeabilization, the neuronal marker staining was performed using appropriate first and secondary antibodies, followed by refixation for $10 \mathrm{~min}$ and denaturation with $2.5 \mathrm{M} \mathrm{HCl}$ for 30 min, followed by BrdU staining and counterstaining with DAPI.

Mitotic index. pH3 staining gave comparable results in snap-frozen and prefixed samples. Prefixed sections were used for quantification because they optimally conserved cytological structure, and $\mathrm{pH} 3$-positive cells (antibodies from Cell Signaling Technology) at the ventricular surface were enumerated by scrolling through the entire section depth. To adjust for changes in shape and size of the ventricular surface between samples, we used a method to estimate the length of the ventricular surface: the length was defined by an estimation of the number of average-sized DAPI nuclei that can be accommodated in the mitotic layer at the ventricular surface in one focal plane. The mitotic index was defined as the number of quantified mitotic cells divided by the estimated length of the mitotic border. This was normalized to $100 \%$ for untreated ctrl samples.

\section{Results}

Lig4 ${ }^{Y 288 C}$ embryos show abnormal neuronal development and increased apoptosis in the $\mathrm{VZ}$ and $\mathrm{SVZ}$ regions

The adult brain of homozygous Lig4 ${ }^{\text {Y288C }}$ mice is smaller than that of $\operatorname{Lig}^{+/+}$or heterozygous littermates, although the gross brain structure is unchanged (data not shown). There was no detectable difference between $\operatorname{Lig} 4^{+/+}$and $\operatorname{Lig} 4^{\mathrm{Y288C/+}}$ genotypes, and we use the term control to represent either genotype. Neuronal developmental delay starts at approximately E14.5, with E15.5 Lig4 ${ }^{Y 288 C}$ embryonic brains appearing smaller and showing thinned neural epithelium compared with ctrls (data not shown). To investigate this further, we analyzed apoptosis by TUNEL staining in E14.5 embryonic forebrains of Lig4 ${ }^{Y 288 C}$ and ctrl embryos. Initially, we examined apoptosis by TUNEL staining using costaining with Tuj1 or Tbr2, respectively, to delineate the distinct regions of the embryonic forebrain (Fig. 2a). Enhanced apoptosis was observed in Lig4 ${ }^{Y 288 C}$ embryos with little apoptosis present in ctrl embryos (Fig. 2a). Moreover, maximum apoptosis in $\operatorname{Lig} 4^{Y 288 C}$ embryos was found in the IZ/CP, but enhanced apoptosis was also evident in the VZ/SVZ. We also examined whether $\mathrm{pH} 3$ staining, which marks the mitotic cell layers, provided an efficient monitor of zone demarcation using $\mathrm{pH} 3$ staining together with the Tuj1 or Tbr2 markers (Fig. 2b). We observed that, at E14.5, Tuj1 labeled the cells basal to the basal mitotic layer, and the Tbr2 ${ }^{+}$cells were encompassed in the mitotically active layer (Fig. $2 b$ ). Because of the clear demarcation of zones by $\mathrm{pH} 3$ staining, subsequent quantification of apoptosis was performed using only $\mathrm{pH} 3$ staining to delineate the VZ/SVZ and IZ/CP regions; the VZ/SVZ was defined as cells up to and including the basal mitotic layer, and the IZ/CP encompassed cells from the basal mitotic layer to the CP (Fig. 2b). At E.14.5, the $\mathrm{CP}$ layer is small, and its inclusion/exclusion in the analysis does not significantly affect the results.

Although enhanced apoptosis was seen at E14.5 in some other embryonic neuronal tissues (e.g., the striatum), it was much less marked in non-neuronal embryonic tissue (e.g., the tongue) (data not shown). Together, consistent with previous reports that germ-line deletion of LigIV confers dramatic neuronal apoptosis in midgestation (Barnes et al., 1998; Frank et al., 2000; Orii et al., 2006; Shull et al., 2009), we detected elevated apoptosis monitored by TUNEL staining in E14.5-E15.5 Lig4 ${ }^{\text {Y288C }}$ embryonic forebrains compared with ctrl littermates. The magnitude of apoptosis in the IZ/CP in the Lig4 ${ }^{Y 288 C}$ embryos is less than that reported in LigIV null embryos, most likely as a result of the residual DSB repair capacity conferred by the Y288C mutation (Orii et al., 2006; Shull et al., 2009).

\section{The VZ/SVZ regions of control embryos show high IR-induced apoptosis, whereas Lig $4^{Y 288 C}$ embryos show greater sensitivity to apoptosis in the IZ}

Next, we examined the magnitude of endogenous and IRinduced apoptosis in the VZ/SVZ and IZ regions in ctrl and Lig4 ${ }^{Y 288 C}$ embryos, focusing on the response to low IR doses (0.05-3 Gy). In ctrl mice, we observed a dose-dependent increase in apoptosis with elevated apoptosis being detectable after exposure to $50 \mathrm{mGy}$ IR. Apoptosis was greater in the VZ/SVZ compared with the IZ, in which marked apoptosis $(>1 \%)$ was only observed after exposure to doses $\geq 0.5$ Gy (Fig. $2 c$ ). In contrast, little apoptosis was observed in the adult brain and other embryonic tissues (e.g., tongue) after these doses (data not shown). 


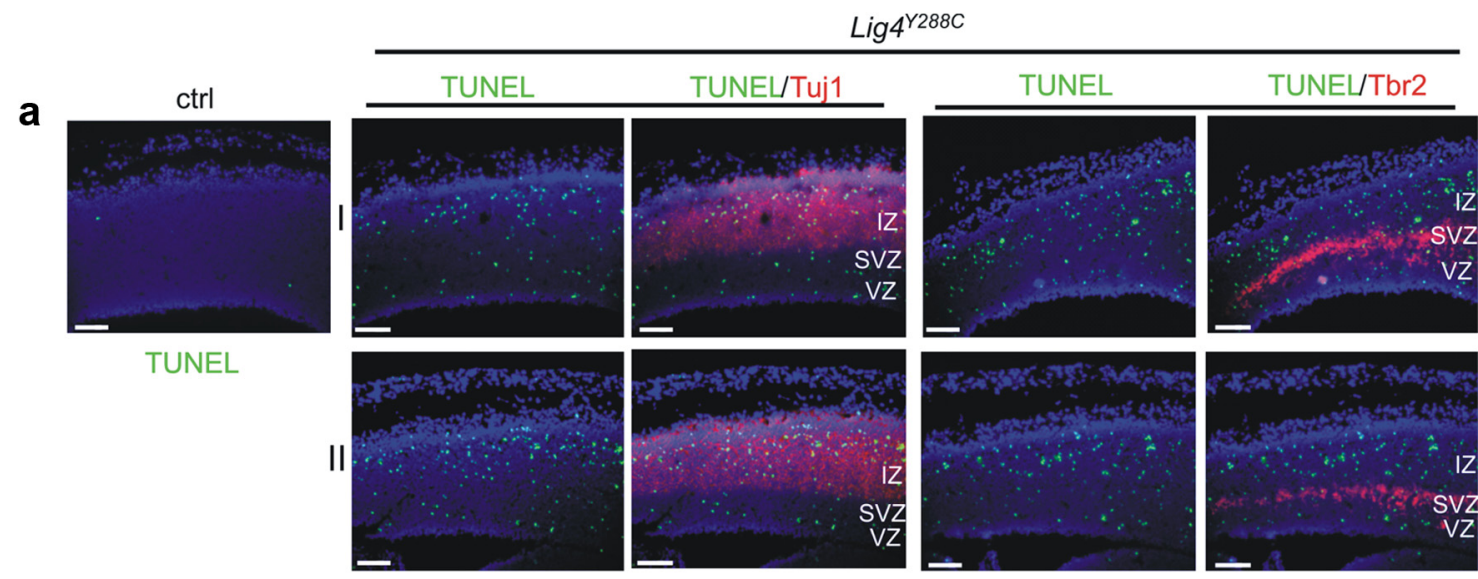

b ctrl

ctrl,

$6 h$ after IR

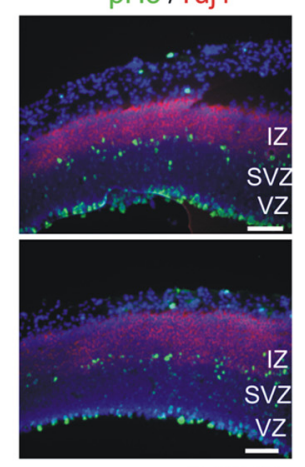

$0.05 \mathrm{~Gy}$

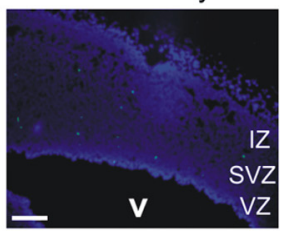

TUNEL

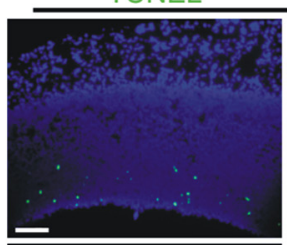

ctrl,

$0.1 \mathrm{~Gy} 6 \mathrm{~h}$

ctrl,

0.1 Gy $14 h$
$\mathrm{pH} 3 / \mathrm{Tbr} 2$

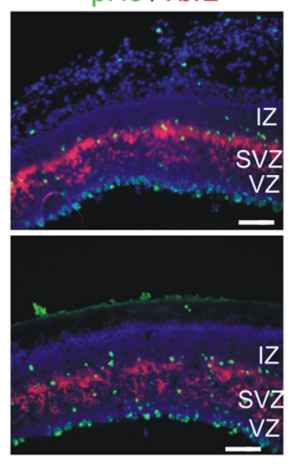

$0.1 \mathrm{~Gy}$

d

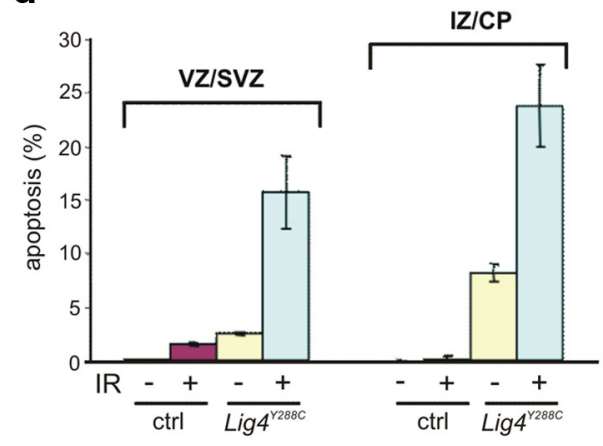

$0.5 \mathrm{~Gy}$

$3 \mathrm{~Gy}$
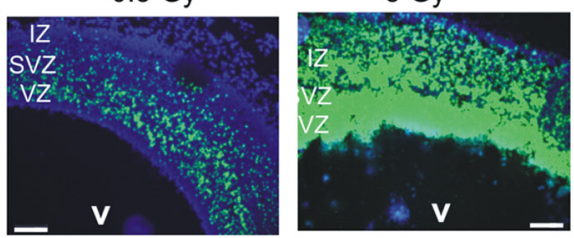

TUNEL/Tbr2
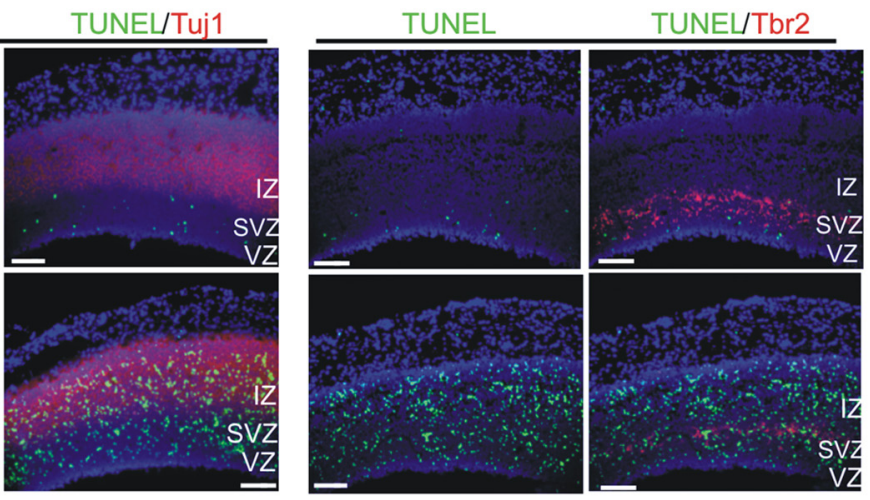

TUNEL/Tui1

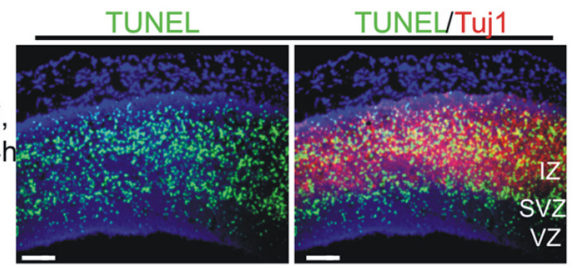

Figure 2. Endogenous and IR-induced apoptosis in ctrl and Lig4 ${ }^{Y 288 C}$ embryonic forebrains. $\boldsymbol{a}$, At E14.5, no significant endogenous apoptosis (TUNEL staining; green) is observed in control forebrains (ctrl), whereas Lig4 ${ }^{Y 288 C}$ embryos show increased apoptosis in the VZ/SVZ and IZ/CP with greater apoptosis being observed in the IZ/CP; representative sections of two Lig $4^{1288 C}$ embryonic forebrains from different litters are shown (I, II). Tuj1 (red) and Tbr2 (red) antibodies are used to visualize the differentiated IZ or the intermediate precursors of the SVZ, respectively. $\boldsymbol{b}$, Costaining of the $\mathrm{G}_{2} / \mathrm{M}$-marker $\mathrm{pH} 3$ (green, antibody from Abcam) with Tuj1 or Tbr2 (red) in ctrl and Lig4 ${ }^{1288 C}$ samples. Tuj1 labels the postmitotic IZ/CP compartment, whereas the intermediate precursors of the SVZ are contained in the mitotically active compartment. c, A dose-dependent increase in apoptosis is observed in the VZ/SVZ and IZ/CP of the forebrains of ctrl embryos $6 \mathrm{~h}$ after IR at E14.5. Greater apoptosis is observed in the VZ/SVZ compared with the IZ/CP. Analysis after exposure to $3 \mathrm{~Gy}$ was from a single embryo. All other analysis, here and elsewhere, was from at least two embryos. d, Quantification of apoptosis in the VZ/SVZ and IZ/CP of forebrains either untreated $(-\mathrm{IR})$ or $6 \mathrm{~h}$ after $0.1 \mathrm{~Gy}(+\mathrm{IR})$ at E14.5. The percentage apoptosis represents (Figure legend continues.) 
Strikingly, both the Lig4 ${ }^{Y 288 C}$ embryonic VZ/SVZ and IZ/CP regions showed enhanced apoptosis after 0.1 Gy compared with ctrl littermates (Fig. 2d,e). IRinduced apoptosis (i.e., subtracting the background level) was similar in the VZ/ SVZ and IZ/CP regions, suggesting that NHEJ functions efficiently in both compartments (Fig. 2d,e). Endogenous apoptosis in the IZ of $\operatorname{Lig} 4^{\mathrm{Y288C}}$ embryos is comparable with that seen $6 \mathrm{~h}$ after $0.5 \mathrm{~Gy}$ in ctrl embryos (Fig. 2a,c). Previous studies have shown that the peak of apoptosis after doses below 0.5 Gy occurs $\sim 6 \mathrm{~h}$ after IR (Hoshino and Kameyama, 1988; Hoshino et al., 1991). In ctrl embryos, apoptosis was reduced $14 \mathrm{~h}$ after $0.1 \mathrm{~Gy}$ but was maintained in the Lig4 ${ }^{\text {Y288C }} \mathrm{VZ/SVZ}$ and enhanced in the IZ/CP (Fig. 2f). Thus, the Lig4 ${ }^{Y 288 C}$ VZ/SVZ and IZ/CP regions are more sensitive to apoptosis than evident from the $6 \mathrm{~h}$ analysis. Because DSBs in Lig4 ${ }^{\mathrm{Y28} C \mathrm{C}}$ mice are more persistent than in ctrl mice as a result of the Lig4 ${ }^{Y 288 C}$ DSB repair defect, these findings suggest that the IZ/CP could be hypersensitive to persistent DSBs.

In summary, although NHEJ functions efficiently to rejoin DSBs in the VZ/SVZ, apoptosis is still readily activated by a low threshold number of DSBs. Apoptosis is less sensitively activated in the IZ/CP region in control mice after radiation exposure. However, in untreated Lig4 ${ }^{Y 288 C}$ mice, apoptosis is sensitively activated by a low number of DSBs in the IZ/CP.

\section{ATM-dependent and -independent mechanisms confer high apoptotic sensitivity in the VZ/SVZ}

Previous studies have demonstrated that apoptosis in the VZ/ SVZ is ATM-independent after high (14 Gy) IR exposure (Lee et al., 2001). Given our finding that NHEJ functions in the VZ/SVZ and that ATM is highly expressed in the VZ/SVZ (Soares et al., 1998; Lee et al., 2001), we examined whether ATM contributes to apoptosis after low IR doses by examining apoptosis in the forebrains of $A T M^{+/-}$and $A T M^{-/-}$littermate embryos (E14.5) $6 \mathrm{~h}$ after in utero irradiation with 0.5 Gy. Strikingly, 75\% of IRinduced apoptosis in the VZ/SVZ was ATM dependent. How-

\section{$\leftarrow$}

(Figure legend continued.) TUNEL-positive cells per 100 nuclei. Quantification was from four to eight sections from two embryos representing 20,000-40,000 nuclei per condition. All quantification given was based on zones differentiated using $\mathrm{pH} 3$ staining. Results represent the average percentage apoptosis for the two embryos; error bars represent SD of the mean between embryos. $\boldsymbol{e}, \mathrm{Lig} 4^{\text {Y288C }}$ embryonic forebrains are hypersensitive to $0.1 \mathrm{~Gy}$ (6 h after IR at E14.5) in the VZ/SVZ and IZ/CP regions compared with the littermate ctrl forebrain (TUNEL staining; green). Additional concomitant Tuj1 (red) or Tbr2 (red) stainings are shown to distinguish the IZ from the SVZ regions. IR-induced apoptosis in Lig4 ${ }^{Y 288 C}$ embryos is more than additive of the endogenous apoptosis plus the IR-induced apoptosis observed in ctrl embryos, demonstrating hypersensitivity of both regions to apoptosis attributable to LigIV deficiency (see quantification in $\boldsymbol{d}$ ). $\boldsymbol{f}$, Apoptosis (TUNEL staining; green) is highly elevated in the VZ/SVZ and IZ/CP of Lig4 ${ }^{\text {Y288C }}$ embryonic forebrains $14 \mathrm{~h}$ after $0.1 \mathrm{~Gy}$ IR at E14.5. Apoptosis in Lig4 ${ }^{\text {Y288C }}$ $\mathrm{IZ/CP}$ is greater at $14 \mathrm{~h}$ compared to $6 \mathrm{~h}$ (additional costaining with Tuj1; red); apoptosis in ctrl embryos is less than at $6 \mathrm{~h}$. Thus, the relative difference is greater at 14 versus $6 \mathrm{~h}$. $\boldsymbol{a}-\boldsymbol{f}$, Representative images of sagittal sections counterstained with DAPI. V, Ventricle. Scale bar, $100 \mu \mathrm{m}$. ever, there was also a clear contribution to apoptosis from an ATM-independent process (Fig. $3 a-c$ ). Consistent with a previous report, IR-induced apoptosis was not observed in the IZ/CP of $A T M^{-/-}$embryos, consistent with the notion that apoptosis in this nonreplicating region is ATM dependent (Lee et al., 2001) (Fig. $3 b, c)$. Importantly, ATM-dependent apoptosis in the VZ/ SVZ (19\%) was greater than in the IZ/CP (6\%), suggesting that there is enhanced sensitivity for activating ATM-dependent apoptosis in the VZ/SVZ (Fig. 3c). In summary, in contrast to studies using high IR doses, we show that ATM significantly contributes to apoptosis in the VZ/SVZ after low doses, although other mechanisms [e.g., ataxia telangiectasia Rad3-related (ATR) signaling at stalled replication forks] also contribute. Thus, ATM detects and senses DSBs in the VZ/SVZ, a finding consistent with high IR-induced apoptosis in the Lig4 ${ }^{Y 288 C} \mathrm{VZ} / \mathrm{SVZ}$ in which DSBs persist as a result of the defect in NHEJ-dependent DSB repair. Thus, ATM and NHEJ function in the VZ/SVZ.

\section{High levels of endogenous DSBs in the VZ/SVZ and IZ in Lig4 ${ }^{\text {Y288C }}$ embryos}

These findings show that, although the VZ/SVZ is highly sensitive to IR-induced apoptosis, apoptosis in $\operatorname{Lig} 4^{Y 288 C}$ embryos is greater in the IZ/CP compared with the VZ/SVZ. This raised the possibility that endogenous DSBs might arise predominantly in the IZ/CP. We, therefore, examined the VZ/SVZ and IZ/CP for the presence of DSBs. Phosphorylated H2AX ( $\gamma \mathrm{H} 2 \mathrm{AX})$ foci formation did not prove to be a suitable marker to monitor DSB formation in the VZ/SVZ because of high background staining and the lack of colocalization with 53BP1 foci, features that most likely arise as a consequence of ATR-dependent $\gamma \mathrm{H} 2 \mathrm{AX}$ activation during replication (Löbrich et al., 2010). Such a difficulty is also observed in cultured S-phase cells. We, therefore, examined 53BP1 foci formation because, in cultured cells, they form at DSBs but not at stalled replication forks (Fig. 1). 53BP1 is expressed endogenously but relocates to form foci after IR. Impor- 


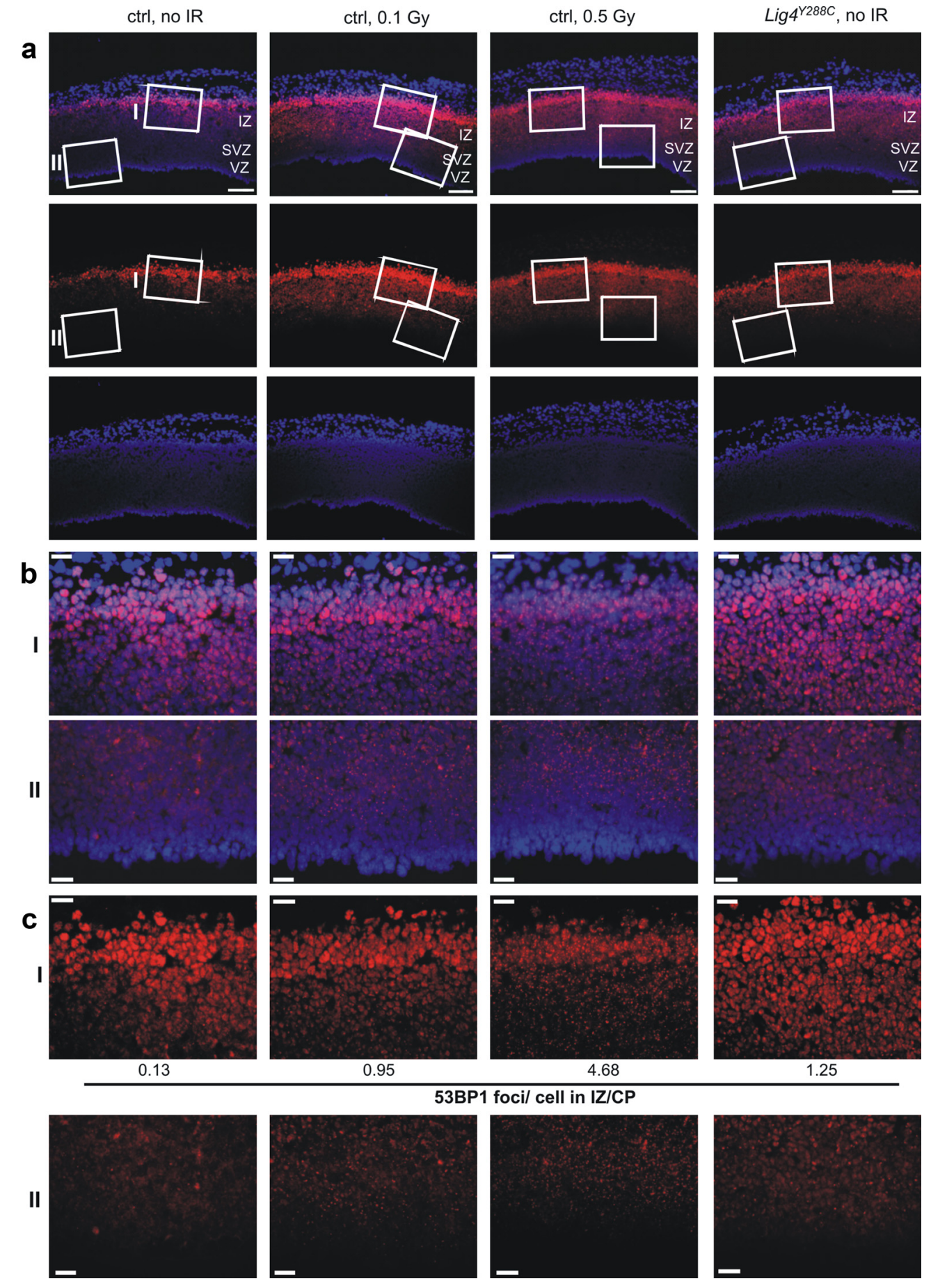

Figure 4. Endogenous and IR-induced 53BP1 foci formation in embryonic forebrains. $\boldsymbol{a}$, IF staining of 53BP1 in E14.5 embryonic forebrains shows a gradient from low to high expression from the VZ at the ventricular surface toward the IZ/CP. The gradient was reproducibly more obvious in Lig $4^{\text {Y288C }}$ mutant embryos (no IR) and after irradiation ( $0.1 \mathrm{~Gy} 1 \mathrm{~h}, 0.5 \mathrm{~Gy} 1 \mathrm{~h}$ ) in ctrls compared with untreated ctrl (no IR) embryos. The stronger evidence of 53BP1 staining in the presence of DSBs is also observed in cultured cells and appears to represent foci formation rather than protein upregulation. The representative images are of sagittal sections: 53BP1 (red) and DAPI (blue) and overlay images are shown (scale bar, $100 \mu \mathrm{m}$ ): areas of the IZ/CP and VZ/SVZ, which are magnified in $\boldsymbol{b}$ and $c$ are highlighted. $\boldsymbol{b}$, Magnification of highlighted areas from $\boldsymbol{a}(\mathrm{I}, \mathrm{IZ} / \mathrm{CP}$ area; II, VZ/SVZ area); overlay of 53BP1 staining (red) and DAPI (blue) demonstrates nuclear staining with 53BP1. The staining is pan nuclear, but defined foci formation is evident after IR particularly in the IZ/CP. Whereas untreated ctrl forebrains show a low number of 53BP1 foci in the VZ/SVZ and IZ/CP, an elevated level of 53BP1 foci can be detected $1 \mathrm{~h}$ after IR ( 0.1 and $0.5 \mathrm{~Gy})$. 53BP1 foci numbers are greater in the IZ/CP region. The foci were difficult to count in the VZ/SVZ region, and only the IZ/CP has been accurately quantified (see c). It is likely that, in the VZ/SVZ, the 53BP1 foci are underestimated particularly after low doses because of the low 53BP1 expression. Untreated Lig $4^{\mathrm{Y} 288 \mathrm{C}}$ embryonic forebrains show elevated 53BP1 foci numbers in the VZ/SVZ and IZ/CP compared with ctrl embryos. The foci numbers in the IZ/CP are comparable with $0.1 \mathrm{~Gy} 1 \mathrm{~h}$; the numbers in the VZ/SVZ appear similar to (although slightly less than) the numbers observed in ctrl embryos exposed to $0.1 \mathrm{~Gy}$. C, Magnification of highlighted areas from $\boldsymbol{a}$ (I, IZ/CP area; II, VZ/SVZ area) for 53BP1 staining (red) only; quantification of 53BP1 foci/cell in the IZ/CP is given below c for I. Number of embryos for quantification were as follows: untreated ctrl and $0.5 \mathrm{~Gy}, n=4 ; 0.1 \mathrm{~Gy}, n=2 ;$ Lig4 $^{\mathrm{r288C}}, n=3$. Scale bar, $20 \mu \mathrm{m}$. 
tantly, although not all $\gamma \mathrm{H} 2 \mathrm{AX}$ foci in the VZ/SVZ were associated with 53BP1 foci, all 53BP1 foci coassociated with $\gamma \mathrm{H} 2 \mathrm{AX}$ (data not shown). Strikingly, at E14.5 we observed a marked gradient in 53BP1 expression extending from low expression in the VZ/SVZ to medium expression in the IZ and high in the incipient CP (Fig. $4 a$ ). Furthermore, expression in the VZ/ SVZ compartment was not homogenous. In untreated ctrl embryos, we observed few 53BP1 foci in the VZ/SVZ and the IZ with elevated foci evident in both regions $1 \mathrm{~h}$ after 0.1 Gy IR (Fig. 4b,c). Although $53 \mathrm{BP} 1$ foci were prominent and readily quantified in the IZ/CP, they were less well defined and less numerous in the VZ/ SVZ. Quantification in the VZ/SVZ was hampered by low 53BP1 expression, nonhomogenous expression, and a high cell density. Furthermore, although 53BP1 foci numbers were dose dependent in the IZ (Fig. 4b,c, I boxes), the response did not appear to be as obviously linear with dose in the VZ/SVZ (Fig. $4 b, c$, II boxes). The findings suggest that we may underestimate DSBs in the VZ/SVZ, particularly at high doses. Because we would expect similar IR-induced DSB induction levels in the VZ/SVZ and IZ [and possibly greater DSB numbers in the VZ/SVZ as a result of a higher percentage of $4 \mathrm{n}$ cells (i.e., cells in late $S / G_{2}$ phase with double the $2 \mathrm{~N}$ DNA content)], we consider that the reduced $53 \mathrm{BP} 1$ foci numbers in the VZ/SVZ are likely a consequence of an impaired ability to detect DSBs (attributable to low 53BP1 expression). Nonetheless, 53BP1 foci are detectable in the VZ/SVZ in unirradiated Lig4 ${ }^{\text {Y288C }}$ embryos, demonstrating that DSBs can arise in this zone. DSB detection in the IZ is approximately twofold to threefold less than observed in cultured cells, although it is consistent with other analyses of foci induction levels in vivo (Rübe et al., 2008).

Despite the difficulty in quantification of 53BP1 foci in the VZ/SVZ, there were clearly elevated 53BP1 foci present in the untreated Lig4 ${ }^{Y 288 C} \mathrm{VZ} / \mathrm{SVZ}$ with levels similar to (although slightly less than) that in ctrl embryos after 0.1 Gy IR (Fig. $4 b, c$, II boxes), Similarly in the IZ region, there were elevated 53BP1 foci in untreated Lig4 ${ }^{\text {Y288C }}$ embryos, and quantification revealed that this was similar to the level in the control IZ region after exposure to $0.1 \mathrm{~Gy}$ (Fig. $4 b, c$, I boxes).

Concomitant 53BP1- $\gamma \mathrm{H} 2 \mathrm{AX}$ analysis in the IZ region endogenously and in irradiated samples showed colocalization consistent with the suggestion that 53BP1 foci represent DSBs (data not shown).

Although the VZ/SVZ quantification was limited, we clearly observed elevated endogenous DSBs in the VZ/SVZ and IZ of Lig4 ${ }^{Y 288 C}$ embryos, with the steady-state level being similar to that induced by 0.1 Gy IR, which from physical studies is estimated to be two to three DSBs per cell (Rydberg, 2000). Interestingly, although 53BP1 foci numbers in the Lig4 ${ }^{Y 288 C}$ IZ were similar to
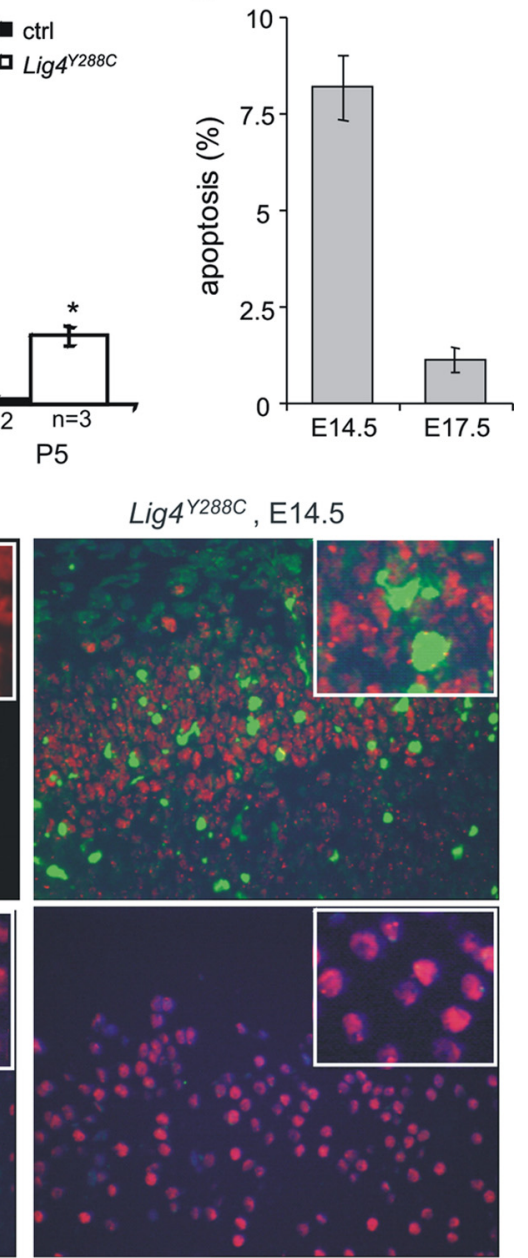

$\operatorname{Lig}^{\mathrm{Y} 288 \mathrm{C}}, \mathrm{P5}$

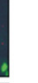

b ctrl, E14.5

ctrl
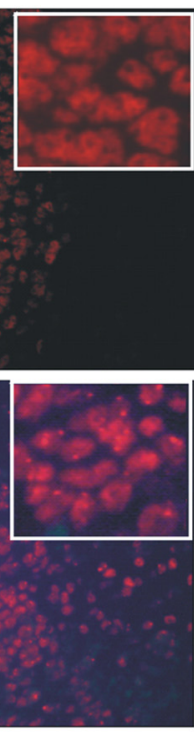

$\operatorname{Lig4}^{\mathrm{Y} 288 \mathrm{C}}, \mathrm{E} 17.5$

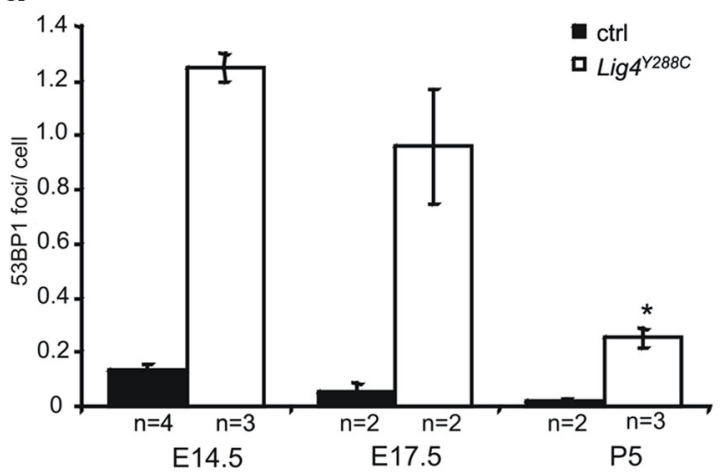

Figure 5. DSB formation and apoptosis correlates with the replicative activity of the developing forebrain. $\boldsymbol{a}, 53 \mathrm{BP} 1 \mathrm{foci}$ were enumerated in the IZ/CP and developing cortex of ctrl and Lig4 ${ }^{Y 288 C}$ animals at E14.5, E17.5, and P5. Number of embryos ( $n$ ) analyzed is given below the respective histogram column. ${ }^{*} p<0.001$ for Lig4 ${ }^{Y 288 C}$ P5 compared with E14.5. b, Apoptosis (percentage) (TUNEL-positive cells/100 nuclei) for Lig4 ${ }^{Y 288 C}$ at E14.5 (as in Fig. 2d) and E17.5 is given. Two embryos were analyzed per time point. C, Images of 53BP1 (red) and TUNEL (green) staining are shown for the IZ/CP region of ctrl and Lig4 ${ }^{Y 288 C}$ sections at E14.5 and for the Lig4 ${ }^{\text {Y288C }}$ developing cortex at E17.5 and P5 (sagittal sections, $40 \times$ magnification; inset, $100 \times$ magnification).

that induced by 0.1 Gy IR, endogenous apoptosis corresponded to that induced by 0.5 Gy IR (Fig. 2). This suggests that endogenous DSBs in the Lig4 ${ }^{Y 288 C}$ IZ have a greater capacity to signal to apoptosis compared with IR-induced DSBs in ctrl mice. This is likely attributable to the persistence of the DSBs in Lig4 ${ }^{\text {Y288C }}$ cells and suggests that the IZ sensitively activates apoptosis from persistent DSBs.

\section{DSB formation and apoptosis in the IZ correlate with VZ/SVZ proliferation}

High apoptosis in $\mathrm{LigIV}^{-/-}$and $\mathrm{XRCC4}^{-/-}$embryos correlates temporally with neuronal generation, i.e., with neuronal stem/ progenitor cell replicative activity (Gao et al., 1998). To gain insight into whether DSB formation and apoptosis in the IZ correlates with VZ/SVZ proliferation, we quantified 53BP1 foci and apoptosis in the IZ/CP at E14.5, in the developing cortex at E17.5, and at P5 in ctrl and Lig4 ${ }^{Y 288 C}$ littermates (Fig. 5a-c). E17.5 represents a time when the VZ/SVZ has just ceased division and by $\mathrm{P} 5$ replication has fully ceased (Mitsuhashi and Takahashi, 
Table 1.53BP1 foci and apoptosis in the neuronal cortex of adult mice

\begin{tabular}{|c|c|c|c|c|}
\hline & \multicolumn{2}{|l|}{$\mathrm{ctrl}$} & \multicolumn{2}{|l|}{$\operatorname{Lig}_{4}^{1 / 288 C}$} \\
\hline & $\begin{array}{l}53 \mathrm{BP} 1 \\
\text { foci/cell }\end{array}$ & Apoptosis & $\begin{array}{l}\text { 53BP1 } \\
\text { foci/cell }\end{array}$ & Apoptosis \\
\hline Untreated $(n=3)$ & 0.02 & $<1.0 \%$ & 0.09 & $<1.0 \%$ \\
\hline 3 Gy $15 \mathrm{~h}(n=1)$ & 1.66 & $<1.0 \%$ & 19.15 & $<1.0 \%$ \\
\hline 10 Gy 15 h $(n=1)$ & 4.49 & $<1.0 \%$ & $>>20.00$ (notquantified) & $\leq 1.0 \%$ \\
\hline
\end{tabular}

Quantification of 53BP1 foci/cell and apoptotis (percentage, measured by TUNEL staining) for ctrl and Lig4 $4^{1 / 288 \mathrm{C}}$ neuronal cortex regions of animals at $3-5$ months of age. All pairs were sex matched and (except 1 untreated pair) were littermate pairs. $n$ represents the number of animals analyzed per condition.

2009). Significantly, in Lig4 ${ }^{Y 288 C}$ embryos, 53BP1 foci numbers are modestly reduced at E17.5 and substantially decreased by P5 (Fig. 5a). This rate of decrease is consistent with the rate of DSB repair observed in $\operatorname{Lig} 4^{Y 288 C}$ mouse embryonic fibroblasts (Nijnik et al., 2007) (data not shown). Thus, the decrease in DSB numbers is consistent with high DSB generation primarily in the VZ/ SVZ/IZ and slow DSB repair in Lig4 ${ }^{Y 288 C}$ embryos. In contrast, apoptosis diminishes more rapidly than 53BP1 foci numbers (i.e., at E17.5 apoptosis is low despite persisting DSBs) (Fig. 5b,c), suggesting that the IZ/CP at E14.5 is hypersensitive to apoptosis compared with the developing cortex at later stages. Consistent with these findings, apoptosis in the developing forebrain in $X R C C 4^{-1-}$ embryos was previously reported to diminish after E15 (Gao et al., 1998).

To further explore the differential tissue sensitivity for DSB induction and apoptosis, we examined DSBs and apoptosis in irradiated 3-month-old mice. Strikingly, although endogenous 53BP1 foci numbers and apoptosis were low in Lig4 ${ }^{Y 288 C}$ mice (demonstrating low endogenous breakage), radiation caused high persisting DSBs but no significant apoptosis (Table 1). Thus, the presence of endogenously generated, persistent DSBs in the Lig4 ${ }^{Y 288 C}$ embryonic brain plus hypersensitivity to activate apoptosis at persistent DSBs underlies the high level of apoptosis.

In contrast, there is a much lower level of formation of DSBs in the neuronal cortex of 3-month-old $\operatorname{Lig} 4^{\mathrm{Y288C}}$ mice as well as an insensitivity to activate apoptosis.

\section{Insensitive $\mathrm{G}_{2} / \mathrm{M}$ checkpoint arrest in the $\mathrm{VZ} / \mathrm{SVZ}$}

In cultured cells, the $\mathrm{G}_{2} / \mathrm{M}$ checkpoint, a damage response that restricts the proliferation of damaged cells, has a defined sensitivity and is not initiated by low doses nor maintained until the completion of DSB repair (Deckbar et al., 2007). Consequently, mitotic breaks arise predominantly in cells released from checkpoint arrest. Using anti-pH3 staining to identify mitotic cells, we observed the expected mitotic zone in the VZ adjacent to the ventricular surface (plus the basal mitotic layer) (Fig. 6a). We observed that $\mathrm{G}_{2} / \mathrm{M}$ checkpoint arrest is fully activated $1 \mathrm{~h}$ after 0.5 Gy IR but is only partially activated after 0.1 Gy (Fig. $6 a, b$ ). The 0.1 Gy dose induces four to six DSBs in $G_{2}$ cells, suggesting that, as in cultured cells, the $G_{2} / M$ checkpoint has a defined sensitivity in vivo (Deckbar et al., 2007). Examination of the duration of arrest showed that mitotic entry occurs $3 \mathrm{~h}$ after $0.5 \mathrm{~Gy}$, and full recovery is observed after $6 \mathrm{~h}$ (Fig. $6 c, d)$. The increased mitotic index at $6 \mathrm{~h}$ compared with unirradiated samples most likely represents the accumulation of $\mathrm{G}_{2}$-phase cells during checkpoint arrest. Because we could not quantify DSBs in $\mathrm{G}_{2}$-phase VZ cells attributable to very low 53BP1 expression, they were enumerated in the IZ 3 and $6 \mathrm{~h}$ after $0.5 \mathrm{~Gy}$ (Fig. $6 d$ ). Assuming a similar rate of DSB repair in the VZ/SVZ and IZ/CP, the presence of DSBs at 3-6 h strongly suggests that the checkpoint is released before the completion of DSB repair.
To investigate this further, we examined $\gamma \mathrm{H} 2 \mathrm{AX}$ foci in mitotic cells after checkpoint release using $\gamma \mathrm{H} 2 \mathrm{AX}$ analysis. 53BP1 was not used because it dissociates from chromatin during mitosis (Nakamura et al., 2010). A total of $36 \%$ of mitotic cells in untreated embryos harbor $\gamma \mathrm{H} 2 \mathrm{AX}$ foci (Fig. 6e). A previous study also observed endogenous $\gamma \mathrm{H} 2 \mathrm{AX}$ foci in undamaged mitotic cells (McManus and Hendzel, 2005). However, $6 \mathrm{~h}$ after 0.5 Gy, when checkpoint release has occurred, $67 \%$ of mitotic cells harbor $\gamma \mathrm{H} 2 \mathrm{AX}$, with $45 \%$ having at least two foci versus $17 \%$ in the ctrl (Fig. 6e). Interestingly, untreated Lig4 ${ }^{Y 288 C}$ mitotic cells show an intermediate phenotype consistent with persisting DSBs. These findings strikingly demonstrate that checkpoint arrest in the VZ cells has a defined sensitivity that allows progression of cells with $\gamma \mathrm{H} 2 \mathrm{AX}$ foci into mitosis. This finding is consistent with a similar mitotic index in Lig4 ${ }^{Y 288 C}$ and ctrl embryos despite elevated DSBs in Lig4 ${ }^{\mathrm{Y} 288 \mathrm{C}}$ cells (data not shown). This quantification of $\gamma \mathrm{H} 2 \mathrm{AX}$ foci was performed on the apical mitotic cells of the VZ. The number of $\gamma \mathrm{H} 2 \mathrm{AX}$ foci in the basal mitotic layer of the SVZ was similar to that found in the VZ mitotic cells, demonstrating that the $G_{2} / M$ checkpoint in the SVZ is also insensitive and that the intermediate precursor cells of the SVZ can similarly progress through mitosis before DSB repair is completed.

\section{Irradiated VZ/SVZ cells can progress to the IZ and undergo apoptosis}

Although the presence of $\gamma \mathrm{H} 2 \mathrm{AX}$ on mitotic chromosomes suggests that they harbor DSBs, it is also possible that $\mathrm{H} 2 \mathrm{AX}$ dephosphorylation lags behind DSB repair. We, therefore, examined directly whether damaged VZ/SVZ cells can transit to the IZ and undergo apoptosis. We injected a standard dose of BrdU into pregnant mice to label S-phase cells and, 30 min later, mock or IR-treated the mice with $0.5 \mathrm{~Gy}$. Embryos were collected 1 or $14.5 \mathrm{~h}$ after IR because the estimated cell cycle time in the $\mathrm{VZ}$ at E14.5 is $15 \mathrm{~h}$ (Mitsuhashi and Takahashi, 2009). The 0.5 Gy dose was chosen as a dose that induced apoptosis but not prolonged checkpoint arrest. Previous and our own pilot experiments with embryos exposed to BrdU for 30 min to $2 \mathrm{~h}$ at E14.5 showed a single broad band of BrdU staining covering the proliferative areas of the VZ/SVZ (Fig. 7a) (Hayes and Nowakowski, 2000; Orii et al., 2006; Sunabori et al., 2008). Importantly, analysis at $1 \mathrm{~h}$ after 0.5 Gy showed that most BrdU-labeled cells in the SVZ coexpress Tbr2 (Fig. 7a), consistent with previous findings (Englund et al., 2005). At $15 \mathrm{~h}$ after BrdU injection, staining of unirradiated embryos for Tbr2 and BrdU revealed that some BrdU-positive cells were basal to the Tbr2-expressing cell layer (Fig. $7 b$ ) and were present in the Tuj1-positive differentiated IZ layer (Fig. 7c). These cells predominantly no longer express Tbr2. These findings are consistent with the presence of S-phaselabeled cells that have progressed into the IZ and differentiated (Fig. $7 b, c$ ). Triple-staining for BrdU, TUNEL, and Tuj1 demonstrated that BrdU treatment alone did not induce apoptosis (Fig. $7 c$ ). Importantly, after exposure to $0.5 \mathrm{~Gy}$ and analysis $14.5 \mathrm{~h}$ later, although the number of BrdU-positive cells is reduced in all regions probably as a result of delayed replication and cell cycle progression, and cell loss attributable to apoptosis, $\sim 10-20 \%$ of the BrdU-positive cells present in the IZ were TUNEL positive (Fig. $7 d, e$ ). BrdU-negative TUNEL-positive cells were also observed, likely representing irradiated IZ cells and/or unlabeled VZ/SVZ-irradiated cells. Studies have suggested that apoptosis in postmitotic neurons occurs via cell cycle reentry and can result in BrdU incorporation (Becker and Guarente, 1991; Kruman et al., 
a

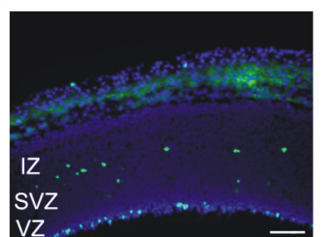

b
0.1 Gy $1 \mathrm{~h}$
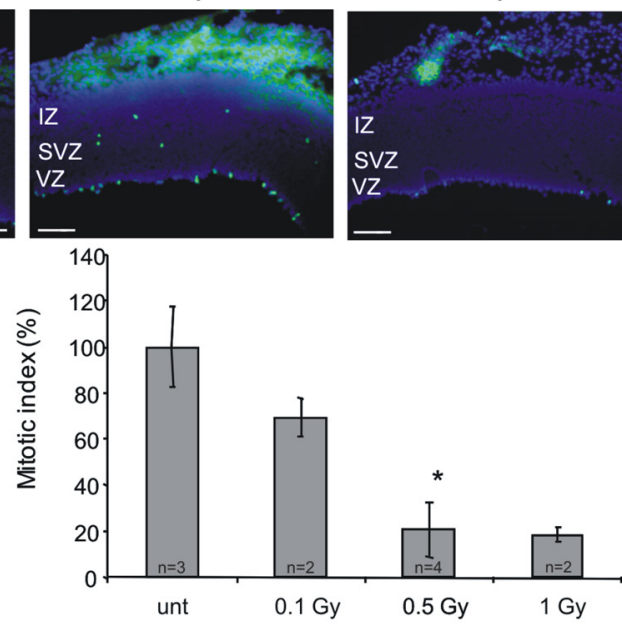

C

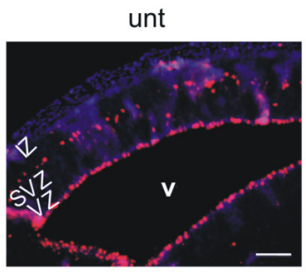

0.5 Gy $1 \mathrm{~h}$

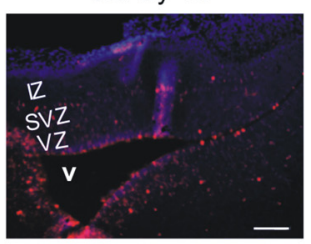

0.5 Gy $1 \mathrm{~h}$

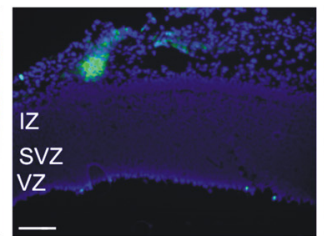

0.5 Gy $3 \mathrm{~h}$

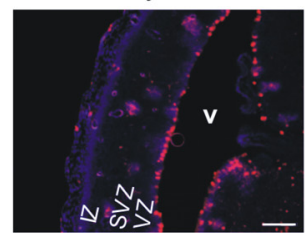

1 Gy $1 \mathrm{~h}$

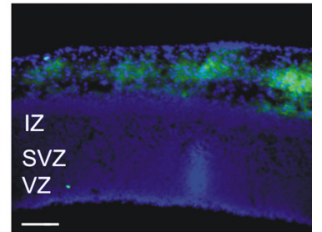

VZ

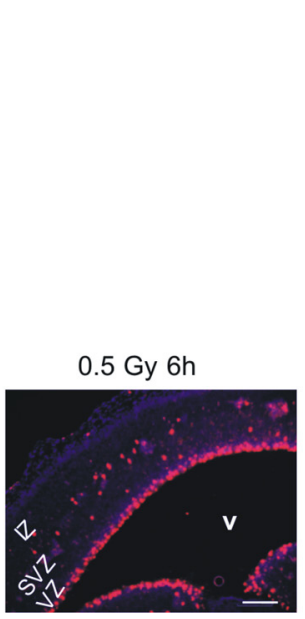

d

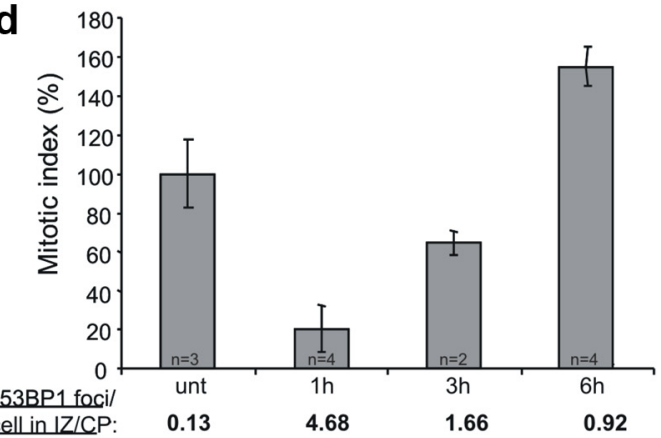

e

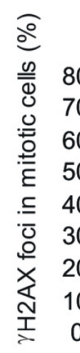

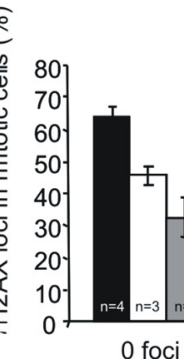

atrl, unt
$\square$ Lig4 $4^{\text {Y288C }}$, unt
$\square$ ctrl, 0.5 Gy 6 h

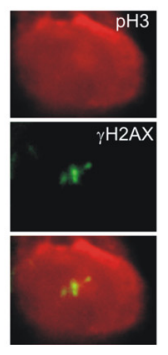

Figure 6. Radiation induced $\mathrm{G}_{2} / \mathrm{M}$ checkpoint induction and release in the neuronal VZ stem cells. $\boldsymbol{a}$, Analysis of mitotic cells in the irradiated embryonic forebrain. Unirradiated ctrl embryos (unt) show abundant pH3-stained cells (green) in the layer adjacent to the ventricular surface; irradiated embryos show diminished pH3-positive cells $1 \mathrm{~h}$ after IR $(0.1,0.5$, or $1 \mathrm{~Gy})$. E14.5, representative snap-frozen sagittal sections, DAPI counterstaining. Scale bar, $100 \mu \mathrm{m}$. $\boldsymbol{b}$, Quantification of mitotic index (MI) $1 \mathrm{~h}$ after exposure to IR doses shown. The MI is normalized to untreated ctrl embryos (unt). n, number of embryos analyzed per data point. ${ }^{*} p<0.001$ for untreated ctrl versus $0.5 \mathrm{~Gy} 1 \mathrm{~h}$. c, Time course for release of $\mathrm{G}_{2} / \mathrm{M}$ checkpoint arrest of ctrl embryos after exposure to $0.5 \mathrm{~Gy}$. E14.5, representative prefixed sagittal sections, $\mathrm{pH} 3$ (red), DAPI counterstaining. V, Ventricle. Scale bar, $100 \mu \mathrm{m}$. This section used anti-pH3 antibody from Millipore in contrast to data in $\boldsymbol{a}$. This antibody detects $G_{2}$-phase cells (weakly staining) as well as mitotic cells (brightly staining). $\boldsymbol{d}$, Quantification of Ml after exposure to 0.5 Gy relative to untreated ctrl embryos (unt) (unt and $1 \mathrm{~h}$ time point as in $\boldsymbol{b}$ ). 53BP1 foci/cell in the IZ/CP at the given time points are also shown; $n$, number of embryos analyzed per time point. Anti-pH3 antibody from Cell Signaling Technology.e, $\gamma H 2 \mathrm{AX}$ foci formation in VZ mitotic cells endogenously and $6 \mathrm{~h}$ after $0.5 \mathrm{~Gy}$. Cells were costained for $\gamma \mathrm{H} 2 \mathrm{AX}$ and pH3. Figure shows the percentage mitotic cells at the ventricular surface with none, one, or at least two

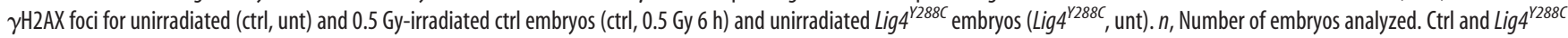
samples were littermate pairs. The inset shows a representative mitotic cell $6 \mathrm{~h}$ after $0.5 \mathrm{~Gy}$ harboring four $\gamma \mathrm{H} 2 \mathrm{AX}$ foci ( $\mathrm{pH} 3$, red; $\gamma \mathrm{H} 2 \mathrm{AX}$, green, separately and as merged image).

2004). We consider it unlikely that this contributes significantly to the $\mathrm{BrdU}^{+} \mathrm{TUNEL}^{+}$cells observed here because BrdU is predominantly cleared for incorporation into DNA by $4-6 \mathrm{~h}$ after injection and our analysis was undertaken at $14.5 \mathrm{~h}$ (Hayes and
Nowakowski, 2000). Thus, collectively, these findings strongly suggest that irreparably damaged cells that are destined for apoptosis can progress from the VZ/SVZ S-phase, through mitosis, and migrate into the IZ in which they undergo apoptosis. 


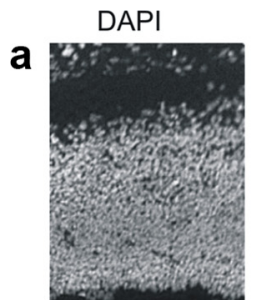

DAPI

b

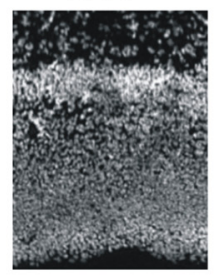

DAPI

C

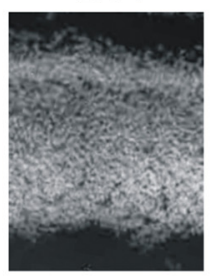

DAPI

d

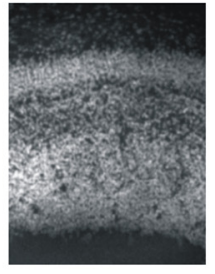

Tbr2

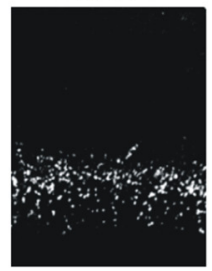

Tbr2

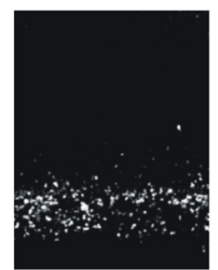

Tuj1

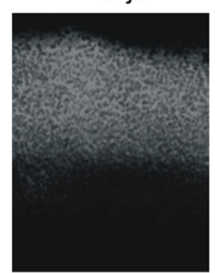

Tuj1

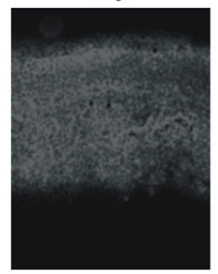

TUNEL

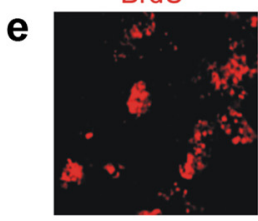

BrdU/TUNEL

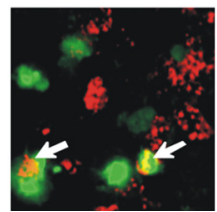

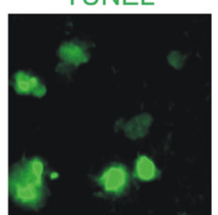

BrdU/TUNEL/Tuji

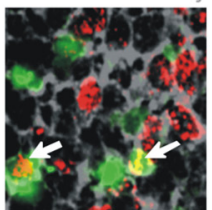

BrdU

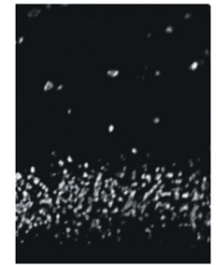

BrdU

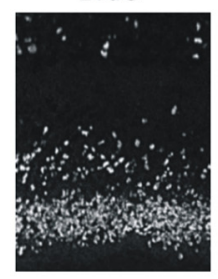

BrdU

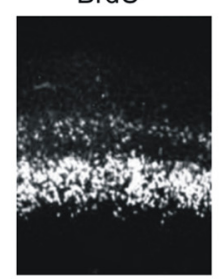

BrdU

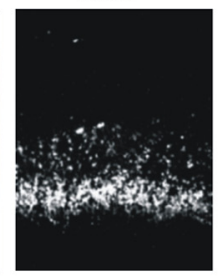

DAPI

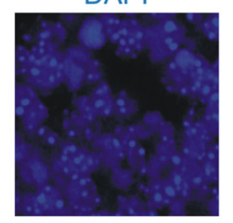

all colours

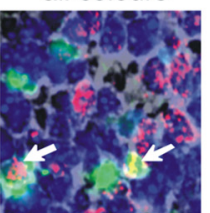

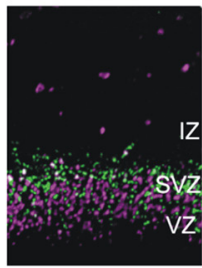
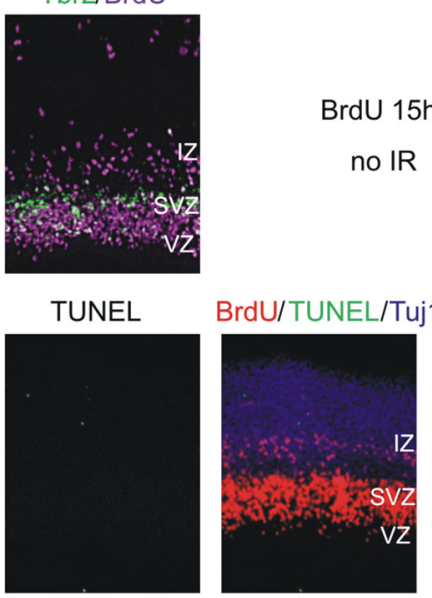$$
\text { NO }
$$

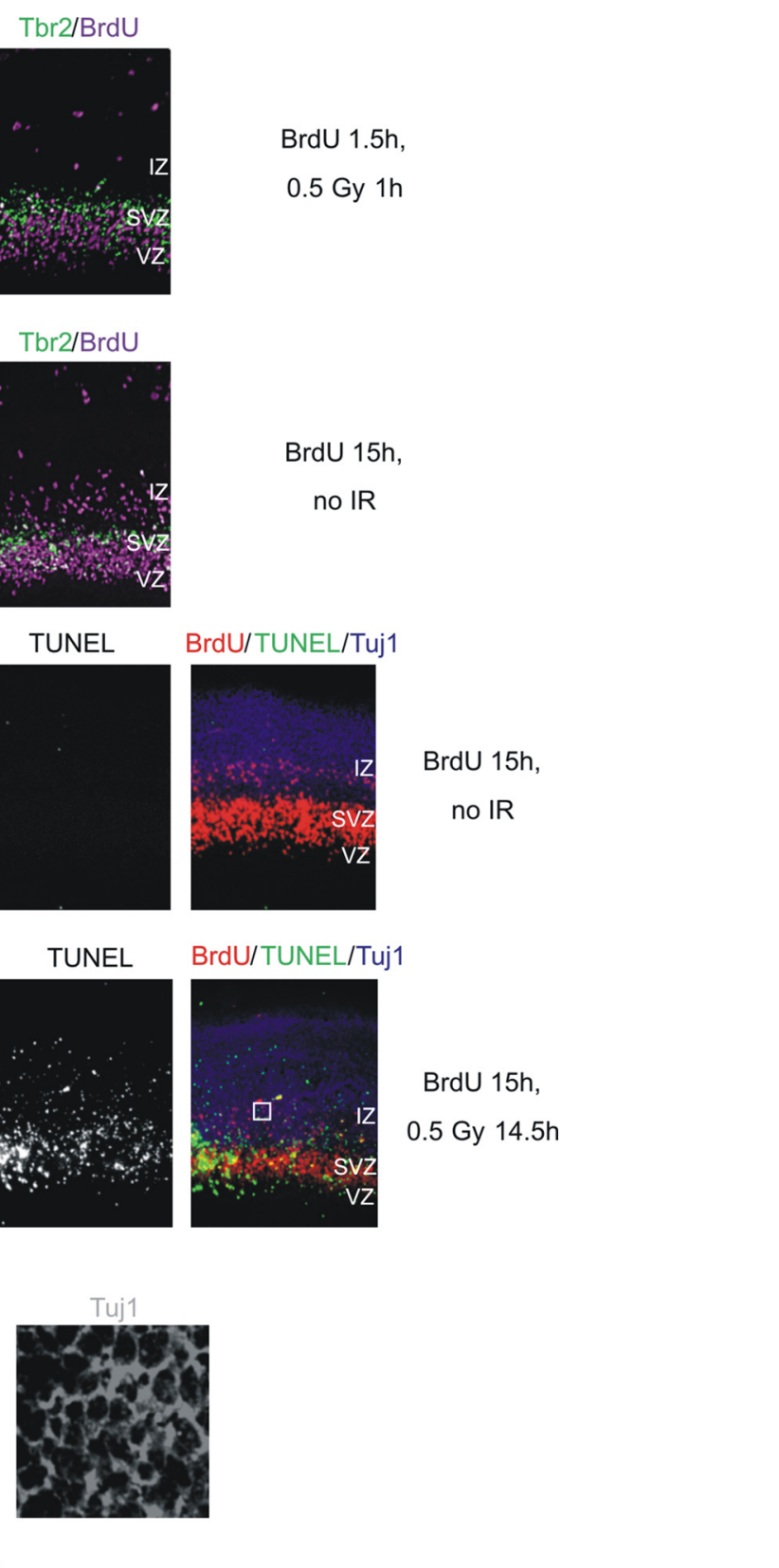

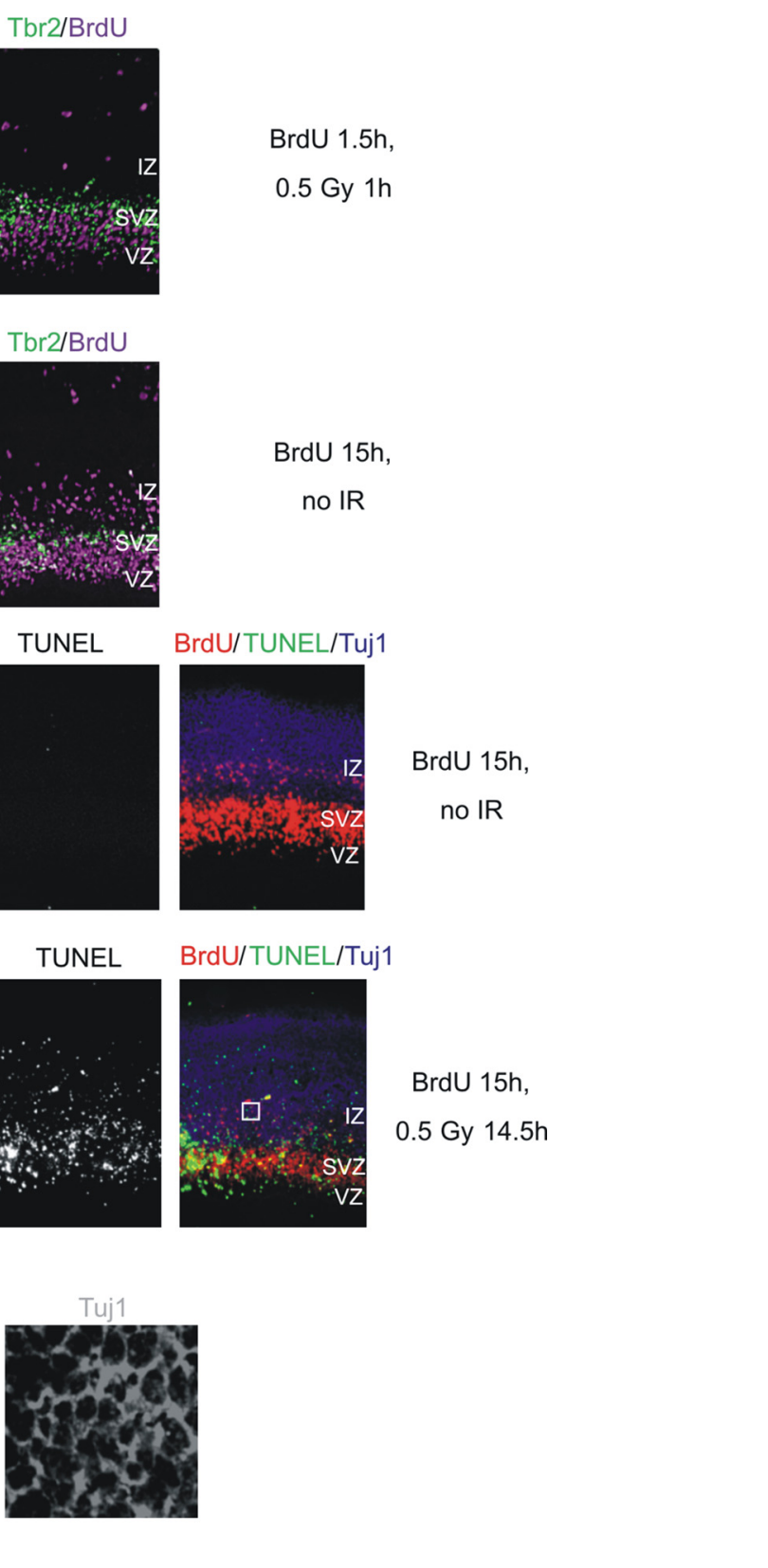

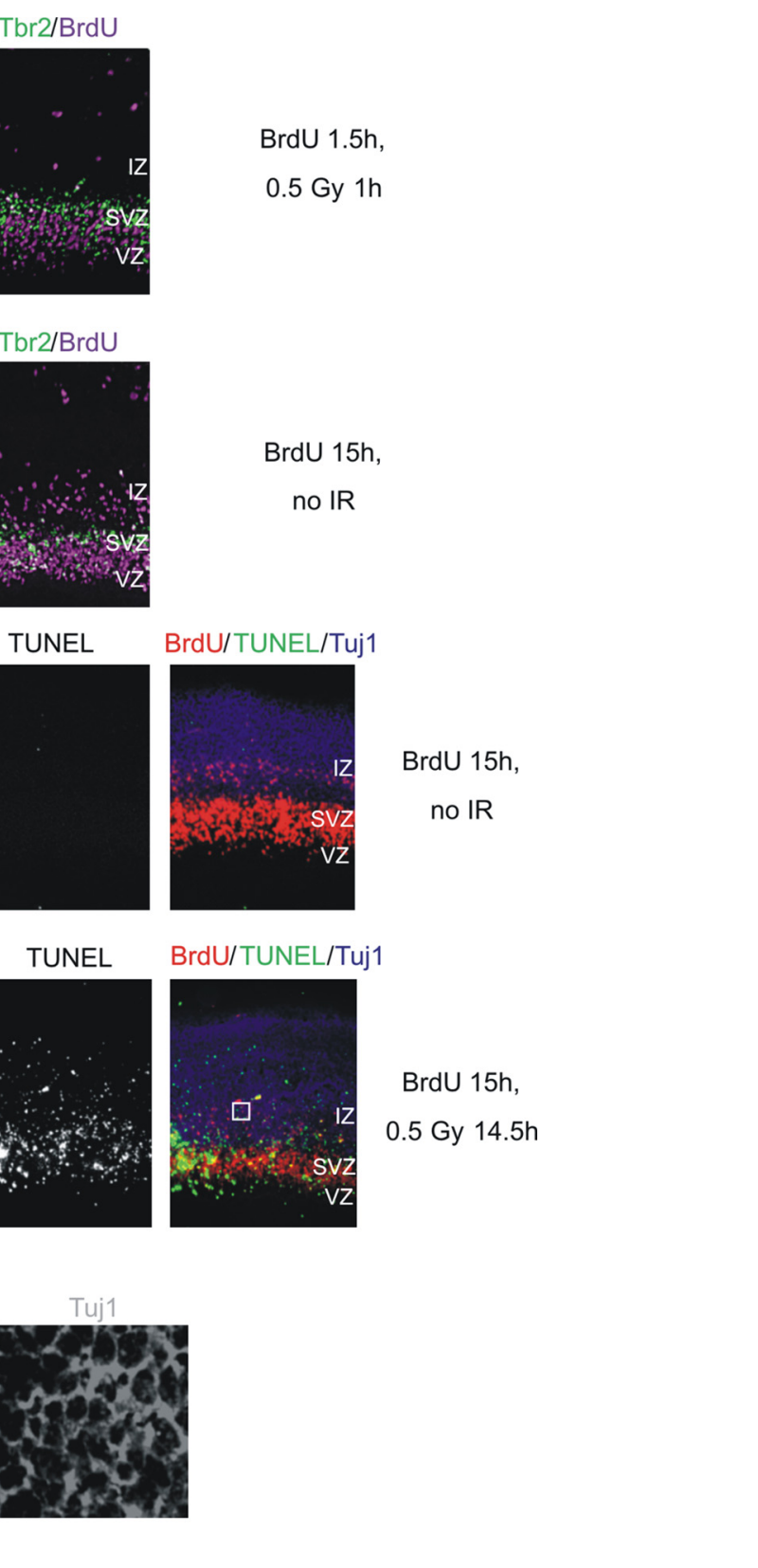

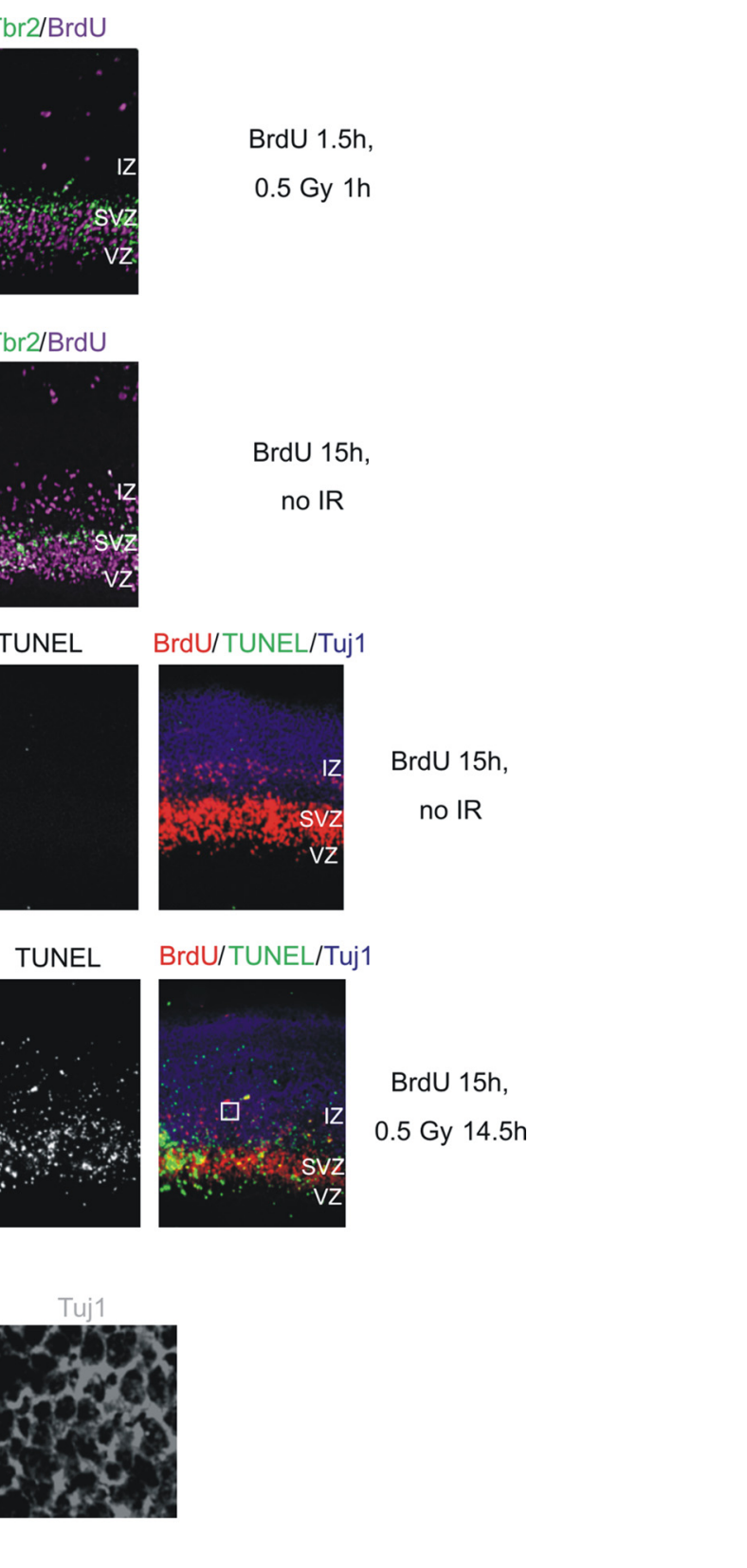

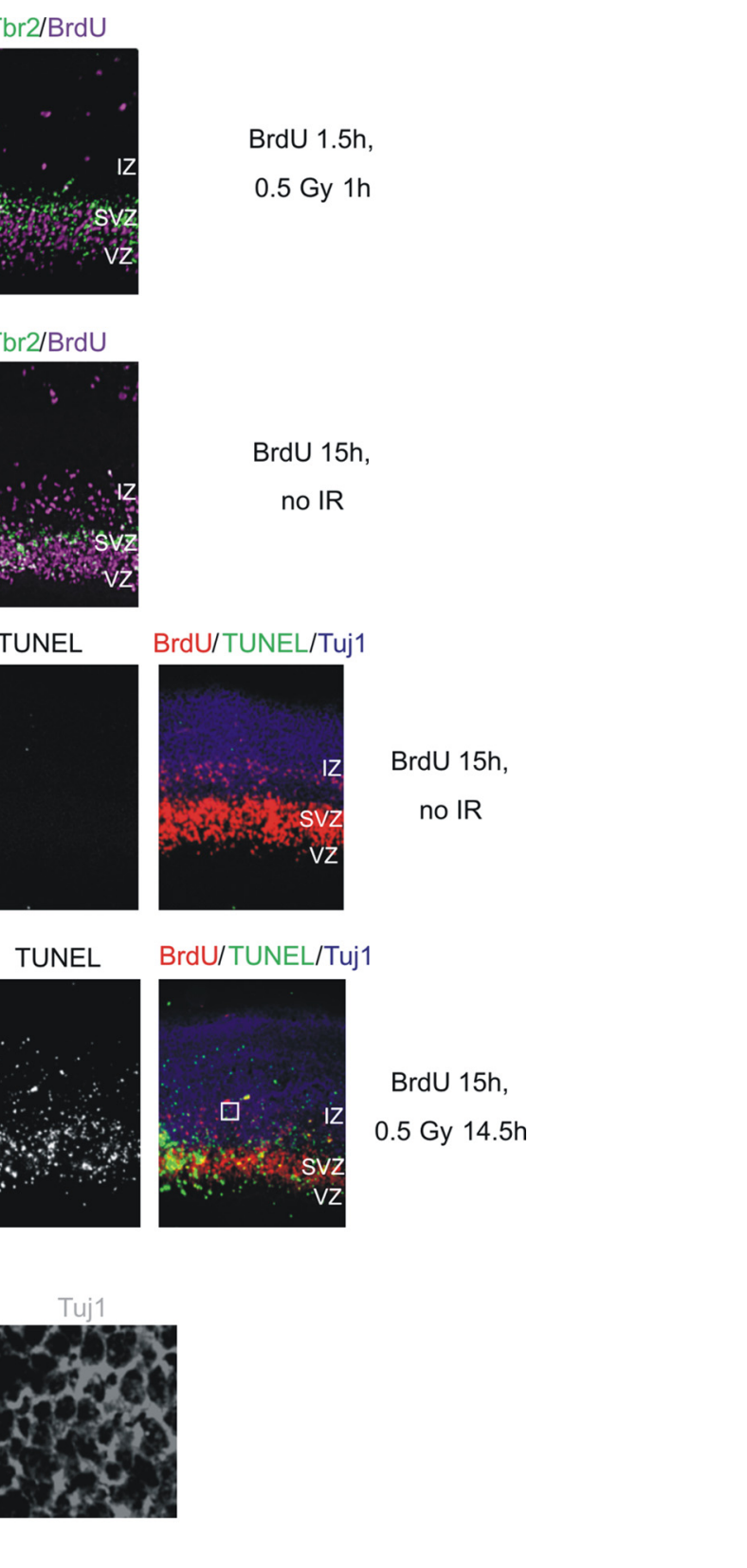

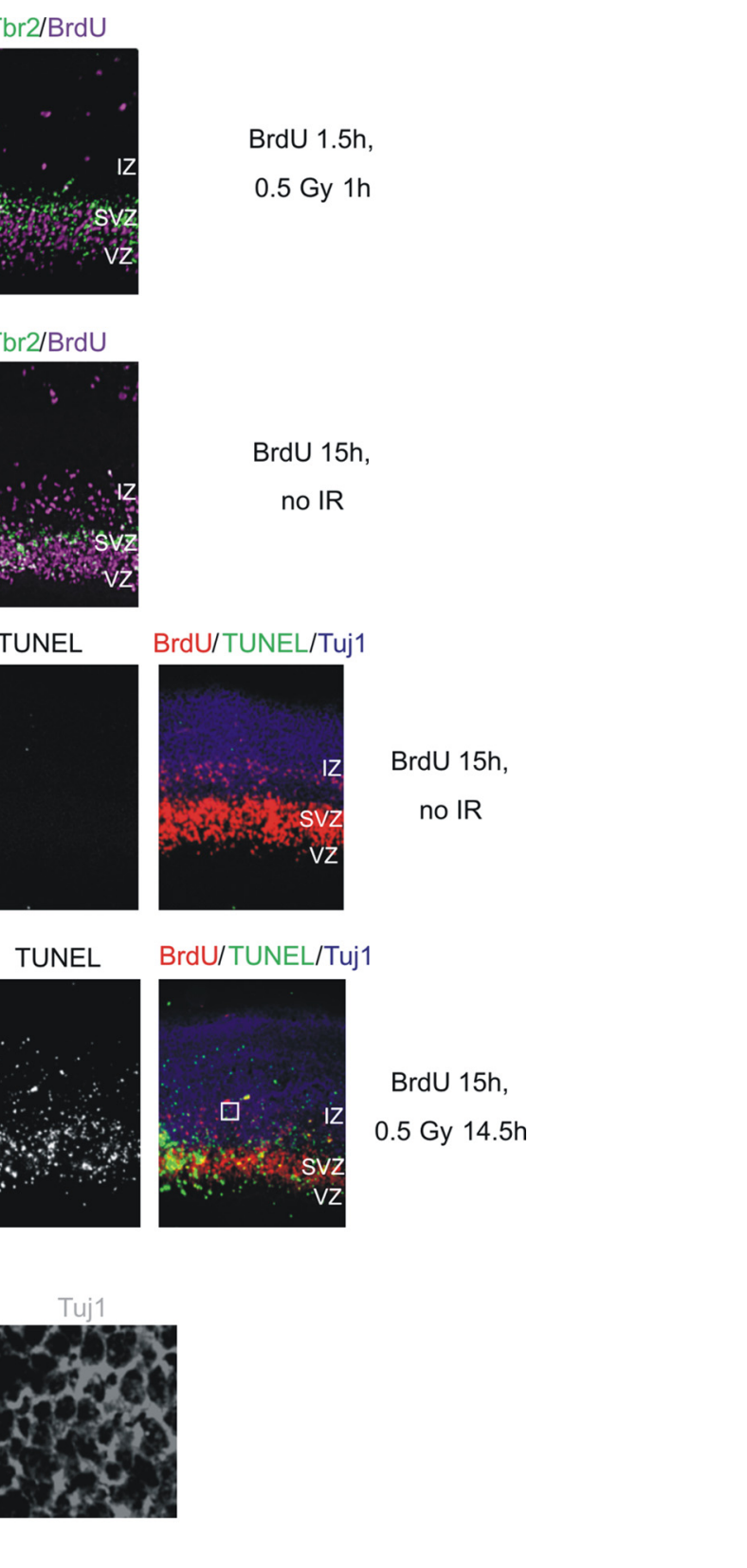

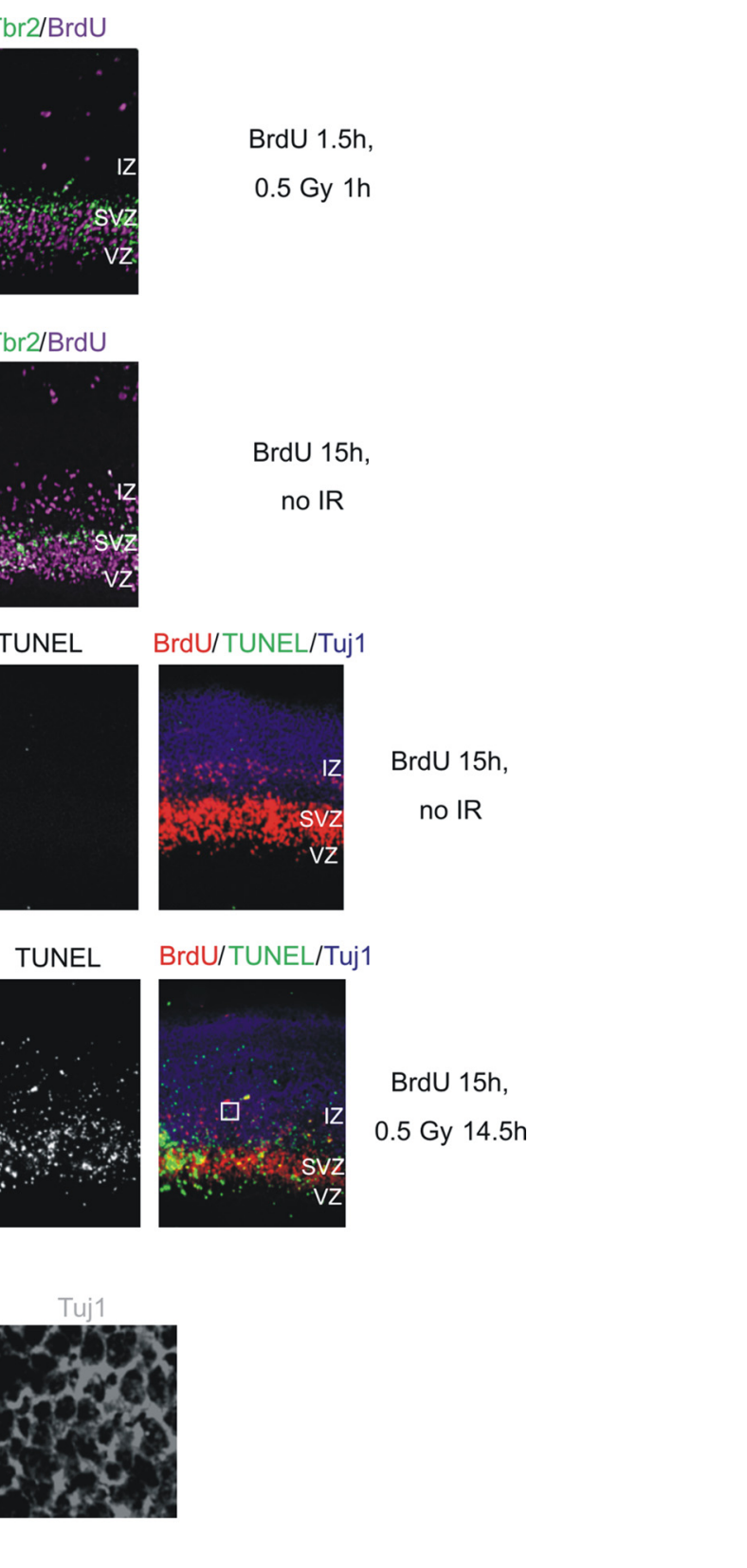

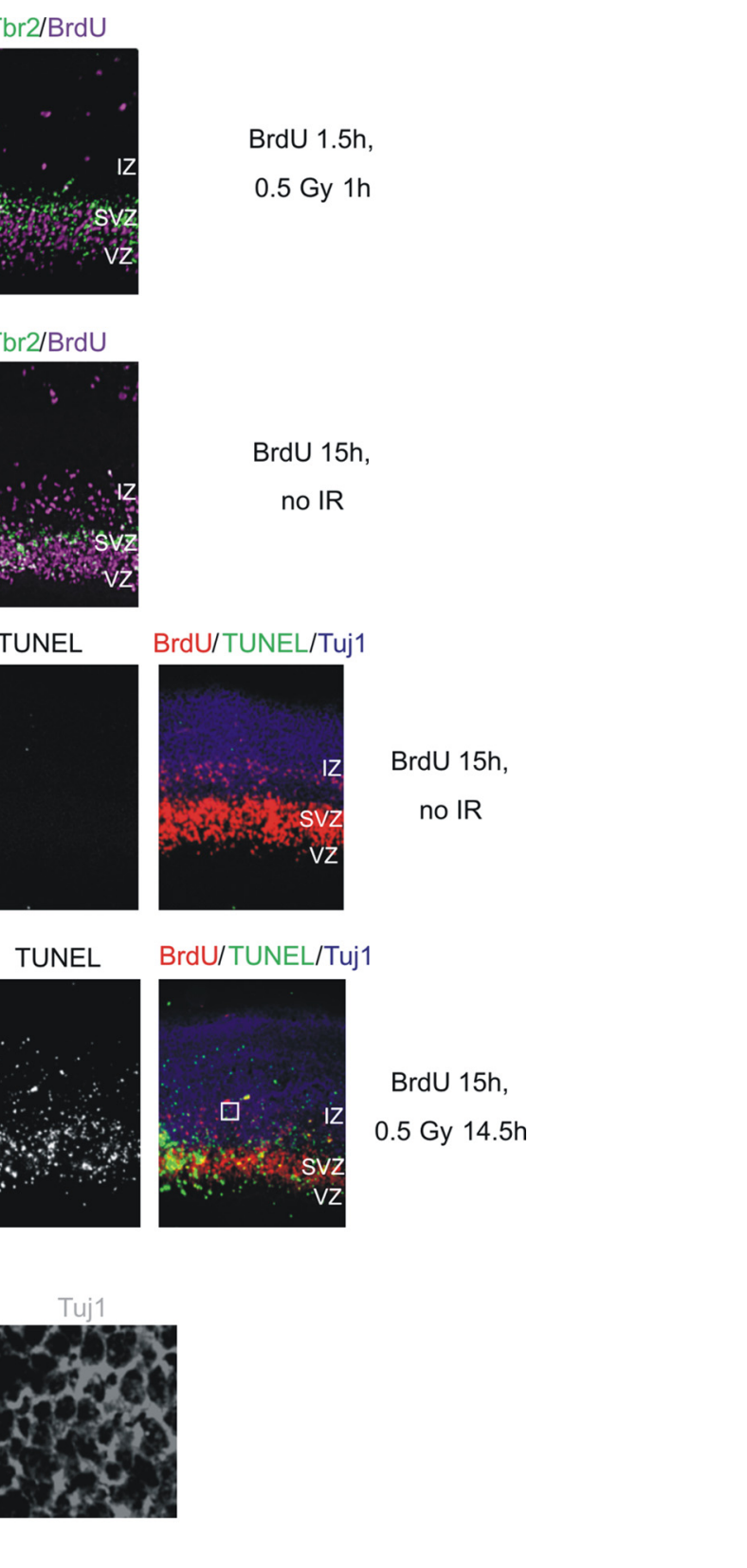
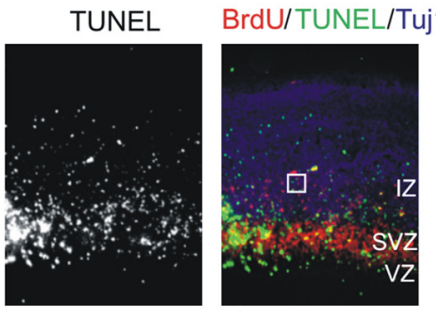

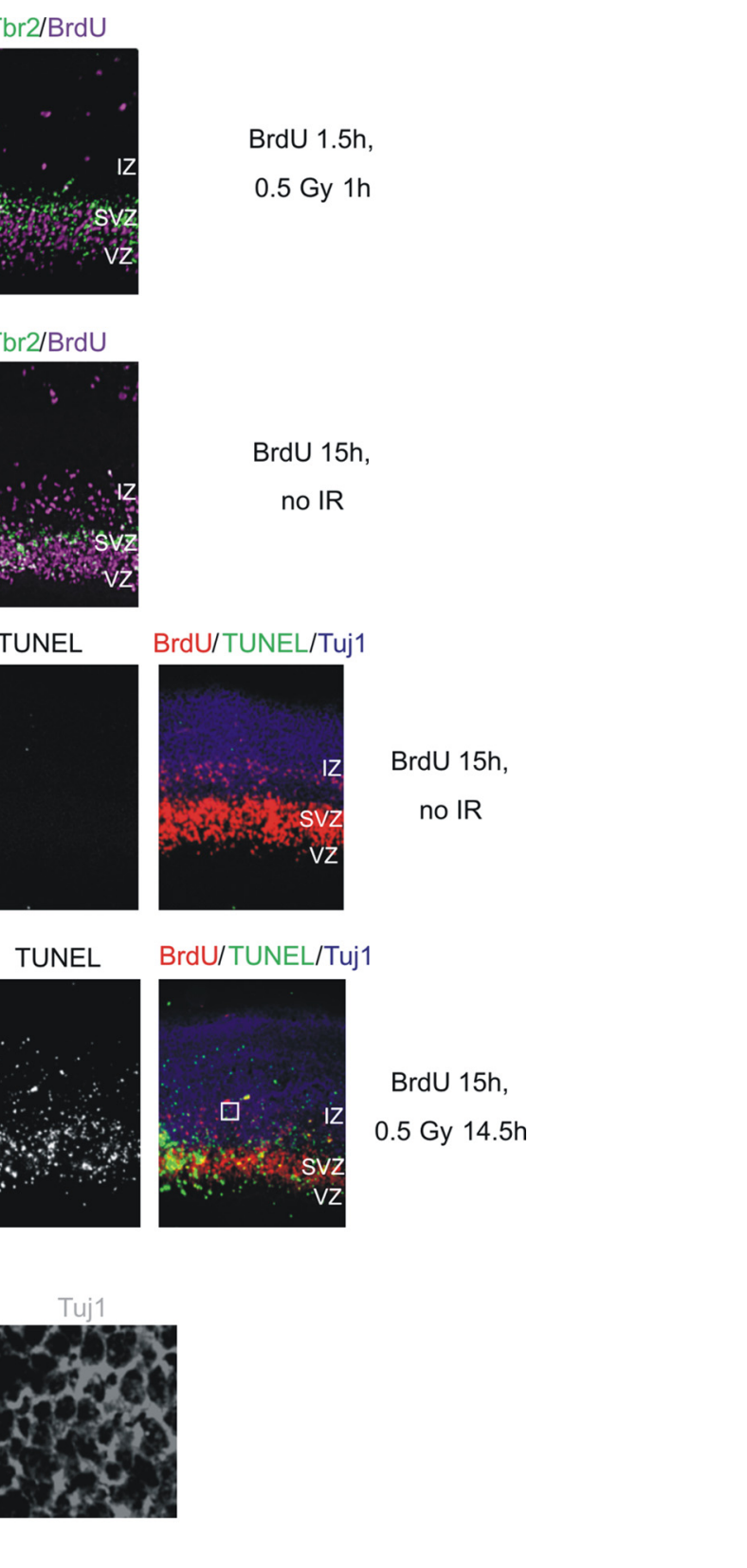

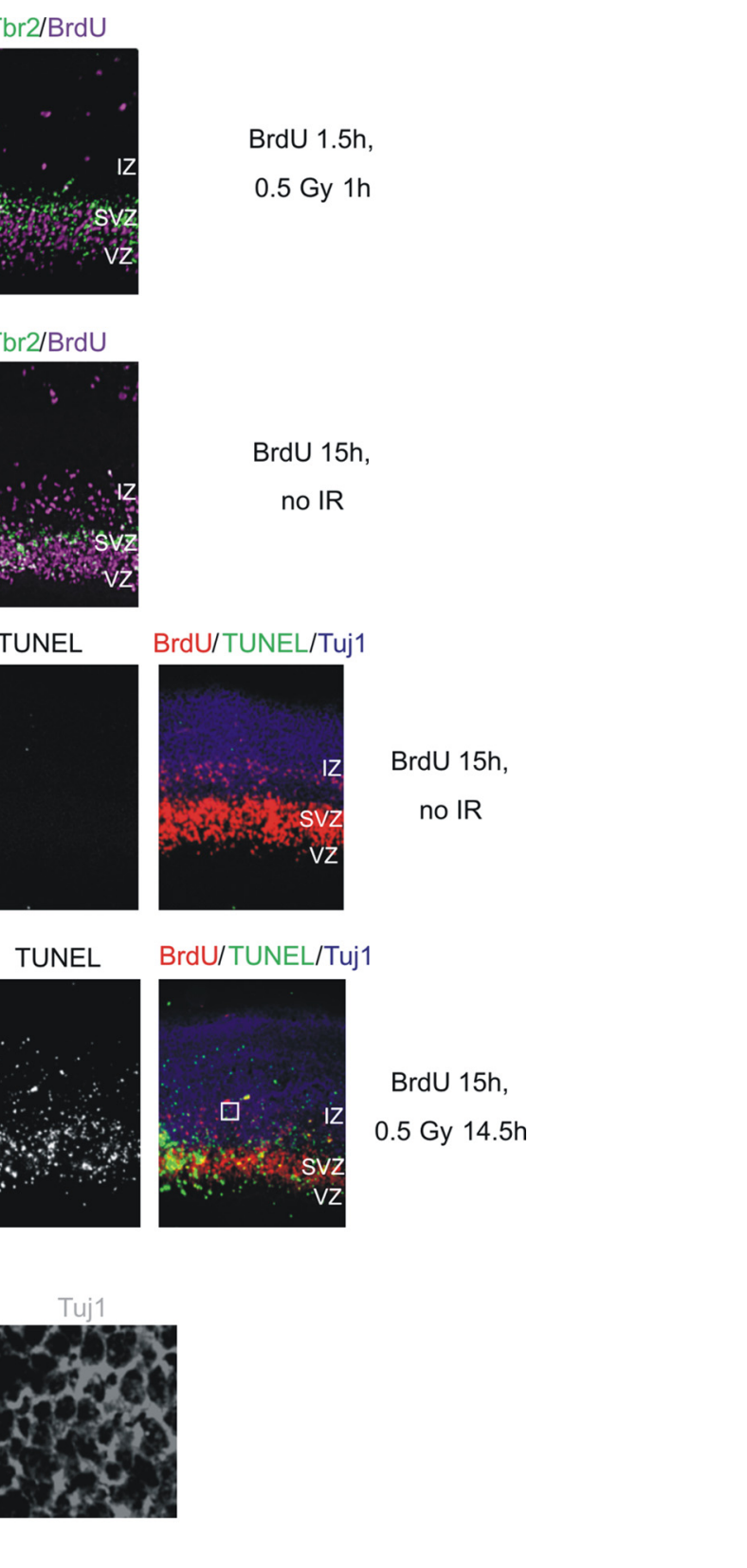

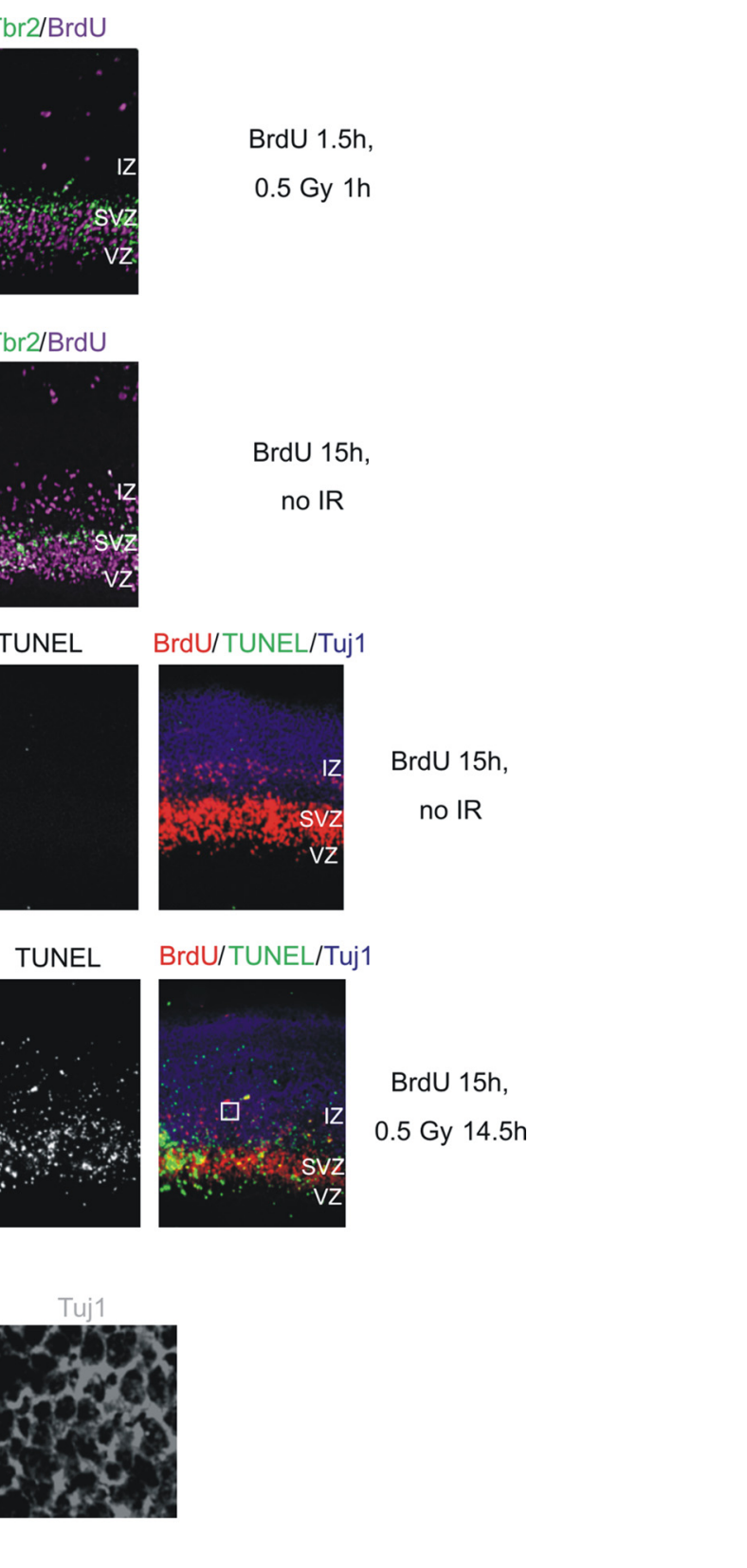

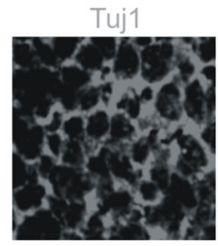

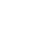




\section{Discussion}

Microcephaly is a marked feature of LIG4 syndrome and XLFdeficiency, suggesting that NHEJ plays a critical role during embryogenesis (O’Driscoll et al., 2001; Buck et al., 2006). Although these features have been demonstrated previously, our aim here is to gain mechanistic insight into the underlying cause, which we achieve by examining DNA breakage, apoptosis, and cell cycle checkpoint arrest in parallel. Furthermore, we focus on the use of physiologically relevant low doses.

Previous studies have shown that the rapidly dividing neuronal VZ/SVZ stem/progenitor cells are highly radiation sensitive between E13.5 and E16.5, when rapid proliferation occurs (Hoshino and Kameyama, 1988; Hoshino et al., 1991). We substantiate these findings and show that apoptosis in the VZ/SVZ can be activated by two to five DSBs because $100 \mathrm{mGy}$ introduces two to three DSBs per cell (Rydberg, 2000; Löbrich et al., 2010). Previous studies using high IR doses have suggested that apoptosis in the VZ/SVZ is ATM independent, although being entirely ATM dependent in the IZ (Lee et al., 2001). However, a more recent study showed diminished endogenous apoptosis in the VZ/SVZ of $A T M^{-1-}$ mice conditionally inactivated for LigIV compared with $\mathrm{ATM}^{+/+} \mathrm{Lig} 4^{\mathrm{Nes}-\mathrm{Cre}}$ mice (Shull et al., 2009). Consistent with the latter finding, we observe that, after $0.5 \mathrm{~Gy}$, apoptosis in the VZ/SVZ occurs via ATM-dependent and ATMindependent processes, with 75\% apoptosis being ATM dependent. Consistent with previous findings, apoptosis in the IZ is entirely (or at least predominantly) ATM dependent. Thus, we suggest that two processes contribute to the high apoptotic sensitivity in the VZ/SVZ; hypersensitivity to ATM-dependent apoptosis at DSBs [which is greater than in the IZ (Fig. 3b)] and an ATM-independent process. The latter could represent ATRactivation at stalled replication or a stress response process (e.g., p38 signaling). Furthermore, we demonstrate that the threshold sensitivity for activating apoptosis diminishes during development from the VZ/SVZ to the IZ/CP, the developing cortex, and is very low in the cortex of 3-month-old mice. We show that NHEJ functions efficiently in the VZ/SVZ and IZ/CP after IR. This is important because repair mechanisms have been suggested to be downregulated in stem cells to preclude the survival of damaged cells (Stambrook, 2007). Although we could not monitor the rate of DSB repair in the VZ/SVZ, the similar magnitude of IR-induced apoptosis in the VZ/SVZ and IZ/CP in Lig4 ${ }^{Y 288 C}$ mice suggests that NHEJ functions similarly in both compartments.

We show a functional $\mathrm{G}_{2} / \mathrm{M}$ checkpoint in the VZ/SVZ but, as in cultured cells, the process is insensitive to low DSB numbers (Deckbar et al., 2007). It is not fully activated after $0.1 \mathrm{~Gy}$ and is released before the completion of DSB repair after higher doses. Importantly, the checkpoint does not prevent irradiated VZ/SVZ cells progressing into the IZ to undergo apoptosis. This represents the first examination of the efficacy of checkpoint arrest in vivo and shows that damaged cells can transit from the stem/ progenitor zone to the differentiated, postmitotic compartment. We conclude that NHEJ and $\mathrm{G}_{2} / \mathrm{M}$ checkpoint arrest function in the VZ/SVZ and that hyper-radiosensitivity is caused by exquisitely sensitive signaling to apoptosis.

Although Lig4 ${ }^{\text {Y288C }}$ embryos show high apoptosis in the IZ/CP as observed in previous studies using $\operatorname{LigIV}^{-1-}$ mice (Barnes et al., 1998; Frank et al., 2000; Orii et al., 2006; Shull et al., 2009), apoptosis is also significantly elevated in the VZ/SVZ. The mutation in Lig4 ${ }^{Y 288 C}$ mice allows slow DSB repair. Thus, the observed DSBs represent steady-state levels between induction and repair. Elevated DSBs in the Lig4 ${ }^{Y 288 C}$ VZ/SVZ/IZ/CP diminish tempo-

\section{a Features}

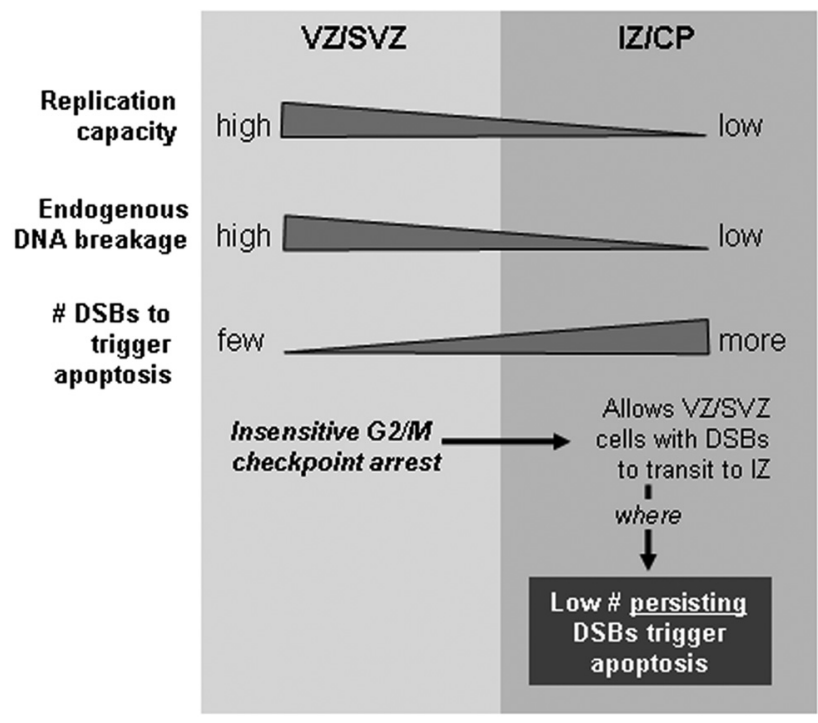

\section{b Apoptotic Sensitivity}

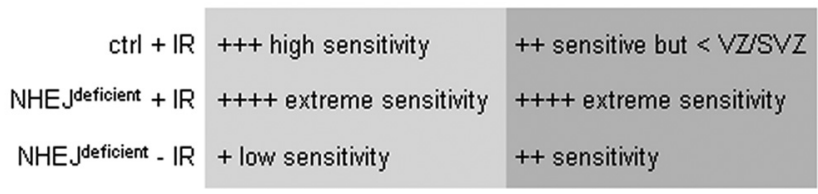

Figure 8. Model for sensitivity of embryonic brain to radiation and Lig/V deficiency. Features of the VZ/SVZ and IZ/CP impact on their response to DNA damage $(\boldsymbol{a})$ and can explain the different apoptotic sensitivities of the VZ/SVZ and IZ/CP in embryonic brains after IR and in NHEJ deficiency, respectively $(\boldsymbol{b})$ : the VZ/SVZ is rapidly proliferating, whereas cells in the IZ are predominantly in $\mathrm{G}_{0} / \mathrm{G}_{1}$-phase. The VZ/SVZ/IZ incurs high levels of endogenous DSBs, which correlate with VZ/SVZ proliferation rate and declines from the IZ to the CP. Hypersensitivity of ctrl embryos to IR exposure is attributable to exquisitely sensitive activation of apoptosis in the VZ/SVZ by ATM-dependent and -independent processes. In contrast, microcephaly in LIG4 syndrome and XLF-deficient patients arises as a consequence of several features: $i$, high DSB induction in the VZ/SVZ/IZ cells attributable to the rapid proliferation rate in the VZ/SVZ; ii, the DSB repair defect that allows the endogenous DSBs to persist; iii, an inefficient $G_{2} / M$ checkpoint that allows cells with persistent DSBs to transit from the VZ/SVZ to the IZ; iv, high sensitivity of the IZ to persistent DSBs. The steady-state level of unrepaired DSBs in LIG4 patients and Lig4 ${ }^{Y 288 C}$ mice must lie below the level activating massive apoptosis or prolonged checkpoint arrest to generate a viable animal. These combined features explain the hypersensitivity of the embryonic brain to Lig/V deficiency.

rally with the arrest of $\mathrm{VZ}$ proliferation, suggesting that $\mathrm{VZ}$ proliferation causes high DSB formation. Although quantification in the VZ is difficult, 53BP1 foci numbers in the Lig4 $4^{Y 288 C} \mathrm{IZ/CP}$ were similar to that induced by 0.1 Gy IR, suggesting a steadystate level of approximately two to three DSBs. A question arising from this work is the origin of the DSBs in the VZ/SVZ/IZ/CP. One possibility is that DSBs originate in the VZ/SVZ because of the rapid replication and that cells with DSBs transit to the IZ. We provide strong evidence to support this model. However, it is also possible that high DSB formation arises in the IZ as a consequence of high metabolic activity in the VZ/SVZ, e.g., IZ cells may maintain high oxidative stress levels. Regardless of their origin, such high DSB formation is not observed in non-neuronal Lig4 ${ }^{\text {Y288C }}$ embryonic tissues (e.g., the tongue) nor in the brain of 3-month-old Lig4 ${ }^{\text {Y288C }}$ mice.

The combined analysis of 53BP1 foci numbers and apoptosis in the embryonic, newborn, and adult neuronal tissues provides insight into the distinct tissue responses to unrepaired DSBs and strongly suggests that the high sensitivity to DSB-induced apo- 
ptosis diminishes during neuronal development and represents a unique feature of the VZ/SVZ and IZ/CP cells.

Why is apoptosis in Lig4 ${ }^{Y 288 C}$ embryos greater in the IZ/CP than the VZ/SVZ, which is not expected if DSBs originate in the VZ/SVZ? Although similar DSB numbers are observed in the Lig ${ }^{Y 288 C}$ VZ/SVZ/IZ/CP and 0.1 Gy irradiated ctrl mice, 0.1 Gy induces little apoptosis in the ctrl IZ/CP. DSBs in Lig4 ${ }^{Y 288 C}$ cells differ from those in ctrl cells because they are persistent as a result of the impact of the Lig4 ${ }^{\mathrm{Y} 28 \mathrm{C}}$ mutation on DSB repair. One possibility is that HR can effect DSB repair in late $S / G_{2}$-phase VZ/ SVZ cells, which does not occur in nonreplicating IZ/CP cells. However, analysis of $\mathrm{G}_{2}$-phase DSB repair in cultured cells from LIG4 syndrome patients exposed a pronounced DSB repair defect, suggesting that HR cannot fully compensate for loss of LigIV (Beucher et al., 2009). Significantly, the steady-state number of DSBs (two to three) in Lig4 ${ }^{Y 288 C}$ mice is lower than the threshold inducing extensive VZ/SVZ apoptosis. Furthermore, two to three DSBs do not activate prolonged $\mathrm{G}_{2} / \mathrm{M}$ checkpoint arrest, and Lig4 ${ }^{Y 288 C}$ and ctrl mice have a similar mitotic index. Moreover, our findings suggest that the IZ/CP may be hypersensitive to persisting DSBs because IR-induced apoptosis in the Lig4 ${ }^{\mathrm{Y} 28 \mathrm{C}}$ VZ/SVZ and IZ/CP regions were similar, in contrast to much lower apoptosis in the IR-treated ctrl IZ/CP, in which DSBs are rapidly repaired. Thus, we propose that, although the VZ/SVZ has exquisite sensitivity to acute DSB formation, the IZ/CP is hypersensitive to persisting DSBs. Interestingly, we observed a gradient in 53BP1 expression with low to higher expression in the VZ/SVZ/IZ/CP. 53BP1 has been reported to amplify ATM signaling and specifically functions in signaling from persistent DSBs (Fernandez-Capetillo et al., 2002; Shibata et al., 2010). However, despite the low 53BP1 levels, ATM-dependent apoptosis is more sensitively activated in the VZ/SVZ compared with the IZ region (Fig. 3c). Thus, this finding would suggest that, although 53BP1 binds to $\mathrm{p} 53$ and is reported to function as a 553 transcriptional coactivator, its reduced expression levels in the VZ/SVZ does not prevent the activation of apoptosis (Iwabuchi et al., 1998). As discussed above, however, there is evidence that 53BP1 might specifically enhances signaling from a low level of persisting DSBs.

Based on these findings, we propose a novel model to explain the distinct sensitivities caused by irradiation and LigIV deficiency (Fig. 8). We suggest that microcephaly in LIG4 syndrome and XLF patients arises as a consequence of two features: high DSB induction in the VZ/SVZ/IZ cells as a consequence of rapid VZ/SVZ replication coupled with a low threshold for undergoing apoptosis in the VZ/SVZ and IZ/CP. Although the VZ/SVZ region is highly sensitive to acute DSB formation, the IZ/CP appears to be sensitive to a low level of persisting DSBs. Because of the insensitivity of the $\mathrm{G}_{2} / \mathrm{M}$ checkpoint, damaged cells with low DSBs can transit into the IZ and undergo apoptosis. The sensitivity of the IZ/CP to persistent DSBs may provide a mechanism to eliminate such damaged cells and in LIG4 syndromes contributes to neuronal cell loss.

These studies provide insight into the interplay between DNA damage responses in the developing brain and their roles in repairing endogenously arising DSBs that can be significant during embryonic development. Given the increased usage of CT scanning and frequency of flying, it is important to understand the magnitude of, and basis underlying, embryonic neuronal sensitivity.

\section{References}

Abner CW, McKinnon PJ (2004) The DNA double-strand break response in the nervous system. DNA Repair (Amst) 3:1141-1147.
Barlow C, Hirotsune S, Paylor R, Liyanage M, Eckhaus M, Collins F, Shiloh Y, Crawley JN, Ried T, Tagle D, Wynshaw-Boris A (1996) Atm-deficient mice: a paradigm of ataxia telangiectasia. Cell 86:159-171.

Barnes DE, Stamp G, Rosewell I, Denzel A, Lindahl T (1998) Targeted disruption of the gene encoding DNA ligase IV leads to lethality in embryonic mice. Curr Biol 8:1395-1398.

Bayer SA, Altman J, Dai XF, Humphreys L (1991) Planar differences in nuclear area and orientation in the subventricular and intermediate zones of the rat embryonic neocortex. J Comp Neurol 307:487-498.

Becker DM, Guarente L (1991) High efficiency transformation of yeast by electroporation. Methods Enzymol 194:182-187.

Beucher A, Birraux J, Tchouandong L, Barton O, Shibata A, Conrad S, Goodarzi AA, Krempler A, Jeggo PA, Löbrich M (2009) ATM and Artemis promote homologous recombination of radiation-induced DNA doublestrand breaks in G2. EMBO J 28:3413-3427

Buck D, Malivert L, de Chasseval R, Barraud A, Fondanèche MC, Sanal O, Plebani A, Stéphan JL, Hufnagel M, le Deist F, Fischer A, Durandy A, de Villartay JP, Revy P (2006) Cernunnos, a novel nonhomologous endjoining factor, is mutated in human immunodeficiency with microcephaly. Cell 124:287-299.

Cairns J (2006) Cancer and the immortal strand hypothesis. Genetics 174:1069-1072.

Deckbar D, Birraux J, Krempler A, Tchouandong L, Beucher A, Walker S, Stiff T, Jeggo P, Löbrich M (2007) Chromosome breakage after G2 checkpoint release. J Cell Biol 176:749-755.

Englund C, Fink A, Lau C, Pham D, Daza RA, Bulfone A, Kowalczyk T, Hevner RF (2005) Pax6, Tbr2, and Tbr1 are expressed sequentially by radial glia, intermediate progenitor cells, and postmitotic neurons in developing neocortex. J Neurosci 25:247-251.

Fernandez-Capetillo O, Chen HT, Celeste A, Ward I, Romanienko PJ, Morales JC, Naka K, Xia Z, Camerini-Otero RD, Motoyama N, Carpenter PB, Bonner WM, Chen J, Nussenzweig A (2002) DNA damage-induced G2-M checkpoint activation by histone H2AX and 53BP1. Nat Cell Biol 4:993-997.

Frank KM, Sekiguchi JM, Seidl KJ, Swat W, Rathbun GA, Cheng HL, Davidson L, Kangaloo L, Alt FW (1998) Late embryonic lethality and impaired $\mathrm{V}(\mathrm{D}) \mathrm{J}$ recombination in mice lacking DNA ligase IV. Nature 396:173-177.

Frank KM, Sharpless NE, Gao Y, Sekiguchi JM, Ferguson DO, Zhu C, Manis JP, Horner J, DePinho RA, Alt FW (2000) DNA ligase IV deficiency in mice leads to defective neurogenesis and embryonic lethality via the p53 pathway. Mol Cell 5:993-1002.

Gao Y, Sun Y, Frank KM, Dikkes P, Fujiwara Y, Seidl KJ, Sekiguchi JM, Rathbun GA, Swat W, Wang J, Bronson RT, Malynn BA, Bryans M, Zhu C, Chaudhuri J, Davidson L, Ferrini R, Stamato T, Orkin SH, Greenberg ME, Alt FW (1998) A critical role for DNA end-joining proteins in both lymphogenesis and neurogenesis. Cell 95:891-902.

Hayes NL, Nowakowski RS (2000) Exploiting the dynamics of S-phase tracers in developing brain: interkinetic nuclear migration for cells entering versus leaving the S-phase. Dev Neurosci 22:44-55.

Hoshino K, Kameyama Y (1988) Developmental-stage-dependent radiosensitivity of neural cells in the ventricular zone of telencephalon in mouse and rat fetuses. Teratology 37:257-262.

Hoshino K, Kameyama Y, Inouye M (1991) Split-dose effect of $\mathrm{X}$-irradiation on the induction of cell death in the fetal mouse brain. J Radiat Res (Tokyo) 32:23-27.

Iwabuchi K, Li B, Massa HF, Trask BJ, Date T, Fields S (1998) Stimulation of p53-mediated transcriptional activation by the p53-binding proteins, 53BP1 and 53BP2. J Biol Chem 273:26061-26068.

Kruman II, Wersto RP, Cardozo-Pelaez F, Smilenov L, Chan SL, Chrest FJ, Emokpae R, Jr., Gorospe M, Mattson MP (2004) Cell cycle activation linked to neuronal cell death initiated by DNA damage. Neuron 41:549-561.

Lee Y, Chong MJ, McKinnon PJ (2001) Ataxia telangiectasia mutateddependent apoptosis after genotoxic stress in the developing nervous system is determined by cellular differentiation status. J Neurosci 21:6687-6693.

Liao MJ, Yin C, Barlow C, Wynshaw-Boris A, van Dyke T (1999) Atm is dispensable for p53 apoptosis and tumor suppression triggered by cell cycle dysfunction. Mol Cell Biol 19:3095-3102.

Löbrich M, Shibata A, Beucher A, Fisher A, Ensminger M, Goodarzi AA, Barton O, Jeggo PA (2010) gamma H2AX foci analysis for monitoring 
DNA double-strand break repair: Strengths, limitations and optimization. Cell Cycle 9:662-669.

McManus KJ, Hendzel MJ (2005) ATM-dependent DNA damageindependent mitotic phosphorylation of $\mathrm{H} 2 \mathrm{AX}$ in normally growing mammalian cells. Mol Biol Cell 16:5013-5025.

Mitsuhashi T, Takahashi T (2009) Genetic regulation of proliferation/differentiation characteristics of neural progenitor cells in the developing neocortex. Brain Dev 31:553-557.

Nakamura AJ, Rao VA, Pommier Y, Bonner WM (2010) The complexity of phosphorylated $\mathrm{H} 2 \mathrm{AX}$ foci formation and DNA repair assembly at DNA double-strand breaks. Cell Cycle 9:389-397.

Nijnik A, Woodbine L, Marchetti C, Dawson S, Lambe T, Liu C, Rodrigues NP, Crockford TL, Cabuy E, Vindigni A, Enver T, Bell JI, Slijepcevic P, Goodnow CC, Jeggo PA, Cornall RJ (2007) DNA repair is limiting for haematopoietic stem cells during ageing. Nature 447:686-690.

O’Driscoll M, Cerosaletti KM, Girard PM, Dai Y, Stumm M, Kysela B, Hirsch B, Gennery A, Palmer SE, Seidel J, Gatti RA, Varon R, Oettinger MA, Neitzel H, Jeggo PA, Concannon P (2001) DNA Ligase IV mutations identified in patients exhibiting development delay and immunodeficiency. Mol Cell 8:1175-1185.

Orii KE, Lee Y, Kondo N, McKinnon PJ (2006) Selective utilization of nonhomologous end-joining and homologous recombination DNA repair pathways during nervous system development. Proc Natl Acad Sci U S A 103:10017-10022.

Pontious A, Kowalczyk T, Englund C, Hevner RF (2008) Role of intermediate progenitor cells in cerebral cortex development. Dev Neurosci 30:24-32.

Rübe CE, Grudzenski S, Kühne M, Dong X, Rief N, Löbrich M, Rübe C (2008) DNA double-strand break repair of blood lymphocytes and nor- mal tissues analysed in a preclinical mouse model: implications for radiosensitivity testing. Clin Cancer Res 14:6546-6555.

Rydberg B (2000) Radiation-induced heat-labile sites that convert into DNA double-strand breaks. Radiat Res 153:805-812.

Sekiguchi J, Ferguson DO, Chen HT, Yang EM, Earle J, Frank K, Whitlow S, Gu Y, Xu Y, Nussenzweig A, Alt FW (2001) Genetic interactions between ATM and the nonhomologous end-joining factors in genomic stability and development. Proc Natl Acad Sci U S A 98:3243-3248.

Shibata A, Barton O, Noon AT, Dahm K, Deckbar D, Goodarzi AA, Löbrich M, Jeggo PA (2010) Role of ATM and the damage response mediator proteins $53 \mathrm{BP} 1$ and $\mathrm{MDCl}$ in the maintenance of $\mathrm{G}(2) / \mathrm{M}$ checkpoint arrest. Mol Cell Biol 30:3371-3383.

Shull ER, Lee Y, Nakane H, Stracker TH, Zhao J, Russell HR, Petrini JH, McKinnon PJ (2009) Differential DNA damage signaling accounts for distinct neural apoptotic responses in ATLD and NBS. Genes Dev 23:171-180.

Soares HD, Morgan JI, McKinnon PJ (1998) Atm expression patterns suggest a contribution from the peripheral nervous system to the phenotype of ataxia-telangiectasia. Neuroscience 86:1045-1054.

Stambrook PJ (2007) An ageing question: do embryonic stem cells protect their genomes? Mech Ageing Dev 128:31-35.

Sunabori T, Tokunaga A, Nagai T, Sawamoto K, Okabe M, Miyawaki A, Matsuzaki Y, Miyata T, Okano H (2008) Cell-cycle-specific nestin expression coordinates with morphological changes in embryonic cortical neural progenitors. J Cell Sci 121:1204-1212.

Takahashi T, Nowakowski RS, Caviness VS Jr (1995) Early ontogeny of the secondary proliferative population of the embryonic murine cerebral wall. J Neurosci 15:6058-6068. 